\title{
Engineering Blue Fluorescent Bulk Emitters for OLEDs: Triplet Har- vesting by Green Phosphors
}

\author{
Simone Hofmann, ${ }^{\dagger} *$ Markus Hummert, ${ }^{\dagger}, \Pi$ Reinhard Scholz ${ }^{\dagger}$, Regina Luschtinetz, ${ }^{\ddagger}$ Caroline Mu- \\ rawski, ${ }^{\dagger}$ Paul-Anton Will, ${ }^{\dagger}$ Susanne I. Hintschich, ${ }^{\dagger, \# ~ J o ̈ r g ~ A l e x, ~}{ }^{\dagger}$ Vygintas Jankus, ${ }^{\S}$ Andrew P. Monk- \\ man, ${ }^{\S}$ Björn Lüssem, ${ }^{\dagger, \Sigma}$ Karl Leo, ${ }^{\dagger}$ and Malte C. Gather ${ }^{\dagger, \Gamma}$ \\ ${ }^{\dagger}$ Institut für Angewandte Photophysik, Technische Universität Dresden, George-Bähr-Straße 1, 01069 Dresden, Germany \\ ${ }^{\ddagger}$ Institut für Physikalische Chemie und Elektrochemie, Technische Universität Dresden, Mommsenstraße 13, 01062 Dres- \\ den, Germany \\ ${ }^{\S}$ Physics Department, University of Durham, South Road, Durham DH1 3LE, United Kingdom
}

KEYWORDS: organic light-emitting diode, triplet harvesting, blue fluorescent emitter

\begin{abstract}
Triplet harvesting in organic light-emitting diodes (OLEDs) from a blue fluorescent to a green phosphorescent emitter is important for the development of highly efficient white OLEDs for lighting applications. Here, we report new blue fluorescent bulk emitters with high triplet energies for triplet harvesting in OLEDs. Based on the chemical structure of the highly efficient blue emitter N,N'-di-1-naphthalenyl-N,N'-diphenyl-[1,1':4',1":4",1"'-quaterphenyl]-4,4"' diamine (4P-NPD), two new quarterphenylene compounds are designed and synthesized. Their experimentally obtained ionization potentials, singlet, and triplet levels are compared to quantum chemical calculations. We show that the incorporation of repulsive methyl groups leads to a twist of the outer phenyl rings of the molecule and increases the triplet level. Finally, triplet harvesting OLEDs comprising these two new compounds as bulk emitters are electrically and optically characterized. We demonstrate that both materials allow triplet harvesting by the green phosphorescent emitter iridium(III)bis(2-phenylpyridinato-N,C2')acetylacetonate ( $\operatorname{Ir}(\mathrm{ppy})_{2}(\mathrm{acac})$ ).
\end{abstract}

\section{Introduction}

Organic light-emitting diodes (OLEDs) are promising candidates for modern lighting and display applications. ${ }^{1,2}$ Due to spin statistics, a singlet to triplet ratio of $1: 3$ is obtained by the recombination of holes and electrons within the OLED structure. ${ }^{3}$ Consequently, in fluorescent emitter systems that emit light only from the singlet state, $75 \%$ of the injected charge carriers are lost. Therefore, major research efforts are dedicated to phosphorescent emitters which have large intersystem crossing rates and emit light efficiently from the triplet state. ${ }^{4}$ While green and red phosphorescent emitters can reach high efficiencies and long lifetimes, the development of a stable blue phosphorescent emitter remains challenging., ${ }^{5,6}$

Furthermore, most blue phosphorescent emitters only achieve sky-blue color coordinates, whereas white light sources need a deep blue component to achieve a high color rendering and meet the requirements for indoor applications. Recently, fluorescent emitters gained much interest due to the efficient upconversion of triplets into singlets, either via thermally activated delayed fluorescence or via triplet fusion. ${ }^{7,8}$ With these promising approaches, one might fully avoid the use of phosphorescent materials one day.

The concept of triplet harvesting (TH) from a blue fluorescent emitter by a green or red phosphorescent material benefits from the deep blue emission and stability of the blue fluorescent emitters while additionally using the radiative triplet state of the phosphor. ${ }^{9,10}$ Here, singlets decay radiatively on the blue fluorescent emitter, while triplets are harvested by the phosphorescent emitter and contribute to the emission at longer wavelengths. This allows designing highly efficient white OLEDs. ${ }^{11,12}$ However, TH by green phosphorescent emitters is particularly challenging since the triplet level of the blue fluorescent emitters needs to be resonant with or above the level of the green phosphor, a requirement that blue fluorescent emitters have not met so far.

In the following, we summarize some of the previous efforts on TH by green emitters. For simplicity, the triplet energy of the different materials involved is approximated by their peak emission wavelength $\lambda_{\max }$, i.e. $\mathrm{T}_{1} \rightarrow \mathrm{S}_{0}=(2 \pi \hbar \mathrm{c}) / \lambda_{\max }$. Sun et $a l .{ }^{9}$ and Kondakova et $a l^{13}$ demonstrated TH using the green phosphorescent emitter fac-tris(2-phenylpyridine) iridium $\left(\operatorname{Ir}(\mathrm{ppy})_{3}, \mathrm{~T}_{1} \rightarrow \mathrm{S}_{0}=2.4 \mathrm{eV}\right)$. In their work, exciton formation occurs on the matrix material 4,4 '-bis(N-carbazolyl)biphenyl $\left(\mathrm{CBP}, \mathrm{T}_{1} \rightarrow \mathrm{S}_{0}=2.61 \mathrm{eV}^{13}\right)$, where the blue emitter is embedded as a dopant. However, the matrix material CBP exhibits a large HOMO-LUMO energy gap (HOMO $<-5.68 \mathrm{eV}^{13}$, LU$\mathrm{MO}=-1.96 \mathrm{eV}^{13}$ ) resulting in high driving voltages and impeding the achievement of high luminous efficacies.

Carbazole based compounds are promising candidates as deep blue bulk emitters with sufficiently high triplet energies to provide TH by $\operatorname{Ir}(\text { ppy })_{3} \cdot{ }^{14,15}$ Yang et al. ${ }^{16}$ showed hybrid white OLEDs with EQEs exceeding $10 \%\left(15 \mathrm{~lm} \mathrm{~W}^{-1}\right)$ using the carbazole/benzimidazole-based compound Cz-2pbb 
$\left(\mathrm{T}_{1} \rightarrow \mathrm{S}_{0}=2.46 \mathrm{eV}\right)$. Recently, Zheng et al. ${ }^{17}$ reported on 7-(diphenylamino)-4-methoxycoumarin (DPMC) and di[4-(4diphenylaminophenyl) phenyl] sulfone (DAPSF) as ambipolar blue bulk emitters with triplet energies above $2.45 \mathrm{eV}$. They demonstrated white OLEDs where green and red emission is obtained by $\mathrm{TH}$, leading to efficiencies comparable to fully phosphorescent OLEDs (max. 22\% EQE, $27 \mathrm{~lm} \mathrm{~W}$ at $1000 \mathrm{~cd} \mathrm{~m}^{-2}$ ). The successful implementation of TH in white OLEDs underpins the importance of developing new fluorescent bulk emitters.

Schwartz et al. ${ }^{18}$ and Rosenow et al. ${ }^{12}$ showed highly efficient white OLEDs with more than $30 \mathrm{~lm} \mathrm{~W}^{-1}$ at a luminance of $1000 \mathrm{~cd} \mathrm{~m}^{-2}$ using doped transport layers ${ }^{19}$ and $\mathrm{TH}$ from the primarily hole transporting blue bulk emitter N,N'-di-1naphthalenyl-N,N'-diphenyl-[1,1':4',1":4",1'"'-quaterphenyl] - 4,4"” diamine (4P-NPD, $\mathrm{T}_{1} \rightarrow \mathrm{S}_{0}=2.30 \mathrm{eV}^{13}$ ).

Figure 1a illustrates the principle of TH using 4P-NPD: Due to the preferred hole transport, excitons are generated next to the hole blocking layer (HBL). Singlets have short lifetimes (ns) and decay radiatively, while triplets have longer lifetimes (ms) and can therefore diffuse towards a phosphorescent emitter doped into 4P-NPD at an appropriate distance away from the generation zone. At the phosphorescent emitter, 4P-NPD triplets are harvested, leading to efficient phosphorescent emission. At the same time, singlet transfer to the phosphor is avoided due to the shorter diffusion length of singlet excitons in 4P-NPD $\left(4-5 \mathrm{~nm}^{20}\right)$ with respect to triplets $\left(11-15 \mathrm{~nm}^{21}\right)$. In this manner, $\mathrm{TH}$ by the red phosphor iridium(III)bis(2methyldibenzo-[f,h]quinoxaline) (acetylacetonate) $\left(\operatorname{Ir}(\mathrm{MDQ})_{2}(\mathrm{acac})\right)$ or by the yellow phosphor bis(2-(9,9dihexylfluorenyl)-1-pyridine)(acetylacetonate) iridium(III) $\left(\operatorname{Ir}(\text { dhfpy })_{2}(\right.$ acac $\left.)\right)$ was demonstrated. ${ }^{10-12,22}$

However, TH from 4P-NPD to a green emitter cannot be realized due to the low triplet level of 4P-NPD. This is illustrated in Fig. 1b which shows the emission spectrum of two 4P-NPD based TH OLEDs comprising either the red emitter $\operatorname{Ir}(\mathrm{MDQ})_{2}(\mathrm{acac})$ or the green emitter $\operatorname{Ir}(\mathrm{ppy})_{2}$ (acac). (Details on the OLED structure are given in the experimental section.) For the device comprising $\operatorname{Ir}(\mathrm{MDQ})_{2}$ (acac), strong red emission is observed in addition to the blue emission of 4P-NPD, which is clear evidence for efficient TH. The device with the green phosphor shows pure 4P-NPD emission without any spectral contribution from the green emitter, demonstrating that TH from 4P-NPD to the green emitter $\operatorname{Ir}(\mathrm{ppy})_{2}$ (acac) cannot be realized. To circumvent this problem, Schwartz et al. ${ }^{18}$ and Rosenow et al. ${ }^{12}$ developed complex stack designs comprising interlayers or stacked (tandem) OLEDs, both of which require a direct recombination of holes and electrons on a green phosphorescent emitter to achieve white light. However, raising the triplet energy of 4P-NPD would enable a much simpler pathway to white TH OLEDs.

In this paper, we investigate ways to increase the triplet level of 4P-NPD by small changes of the molecular structure. Based on these considerations, two deep blue fluorescent bulk emitters, 2,2',2"',3",5",6,6',6"'-octamethyl-N4,N4"'-di(naphthalen-1yl)-N4,N4"'-diphenyl-[1,1':4',1":4",1"'-quaterphenyl]-4,4"'diamine (8M-4P-NPD) and N4,N4"'-bis(9,9-dimethyl-9Hfluoren-2-yl)-2,2',2"',3",5",6,6',6"'-octamethyl-N4,N4"'diphenyl-[1,1':4',1":4",1"'-quaterphenyl]-4,4"'-diamine (8M-4P-FPD), are developed and characterized in terms of crystal structure and energy levels. For both new materials, we demonstrate OLEDs with TH from the blue bulk emitter to the

green phosphorescent emitter iridium(III)bis(2phenylpyridinato-N,C2') acetylacetonate $\left(\operatorname{Ir}(\mathrm{ppy})_{2}(\mathrm{acac})\right)$ which has recently been found to provide superior electroluminescence performance in comparison to the commonly used $\operatorname{Ir}(\mathrm{ppy})_{3} \cdot{ }^{23}$ a) blue fluorescent bulk
emitter (4P-NPD)

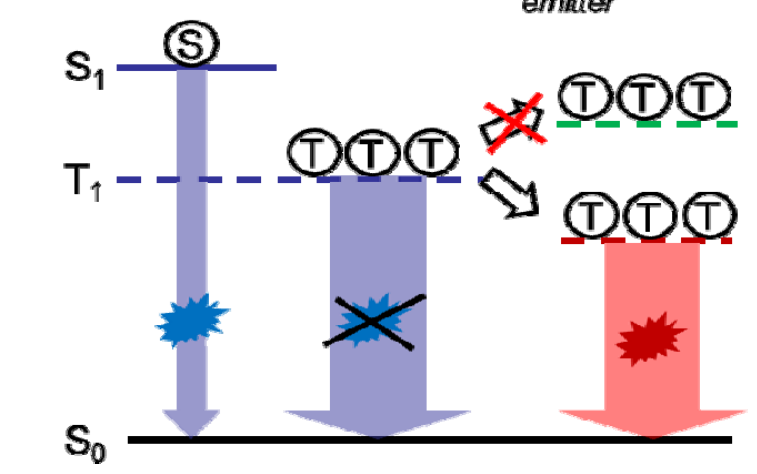

b)

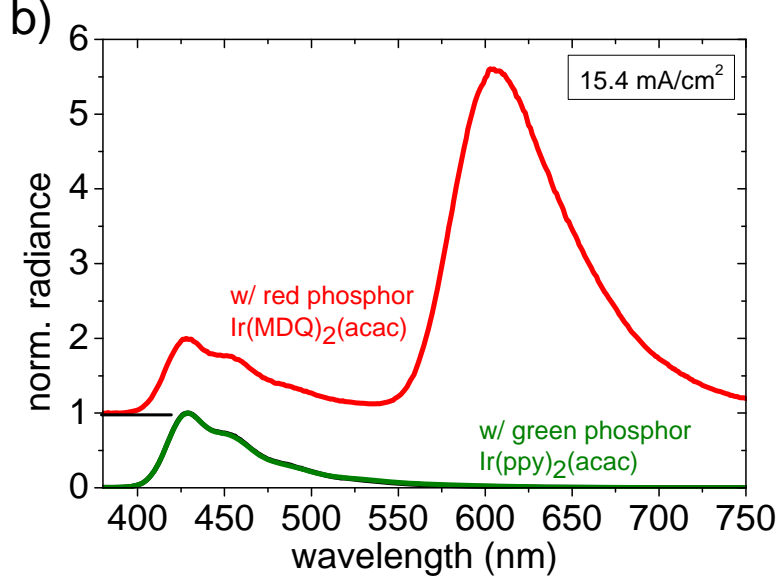

Figure 1. (a) Principle of triplet harvesting using the blue fluorescent bulk emitter 4P-NPD. The high triplet energy of the green phosphorescent impedes triplet harvesting from the blue fluorescent emitter. (b) Emission spectra of TH OLEDs with 4P-NPD and a red or green phosphorescent emitter. For the red emitter a strong spectral contribution is observed, whereas the device with the green emitter shows no emission from the green phosphor. The spectra are normalized with respect to the 4P-NPD emission peak and are vertically displaced for clarity.

\section{Emitter Design}

Our strategy to increase the 4P-NPD triplet level is the modification of the central quarterphenyl core of 4P-NPD in such a way that the dihedral angles between adjacent phenyl rings are increased.

Figure 2a shows the molecular structure of 4P-NPD and the calculated ground state and excited state energy of the molecule as a function of twisting angle $\varphi$ between the central and the peripheral phenyl ring of the quarterphenyl chain. The transition energy for excitation to the lowest excited singlet level $\left(\mathrm{S}_{1} \leftarrow \mathrm{S}_{0}\right)$ and to the lowest triplet level $\left(\mathrm{T}_{1} \leftarrow \mathrm{S}_{0}\right)$ are also shown. The dihedral angle in the central biphenyl group was 
kept fixed at its optimized ground state value of $\alpha=36^{\circ}$ for this calculation. See Sec. 8 at the end of this paper for details on the quantum chemical calculation.

The ground state energy of $4 \mathrm{P}-\mathrm{NPD}$ is lowest for a twisting angle of $\varphi=35^{\circ}$, indicating that this is the most likely configuration of the molecule. For larger twisting angles, the energy of the $T_{1}$ and the $S_{1}$ increase significantly. Both transition energies $\left(S_{1} \leftarrow S_{0}\right.$ and $\left.T_{1} \leftarrow S_{0}\right)$ grow monotonously with $\varphi$ so that the $S_{1}$ and $T_{1}$ states have potential surfaces with a minimum at a slightly lower value of $\varphi$ with respect to the ground state potential $\mathrm{S}_{0}$.

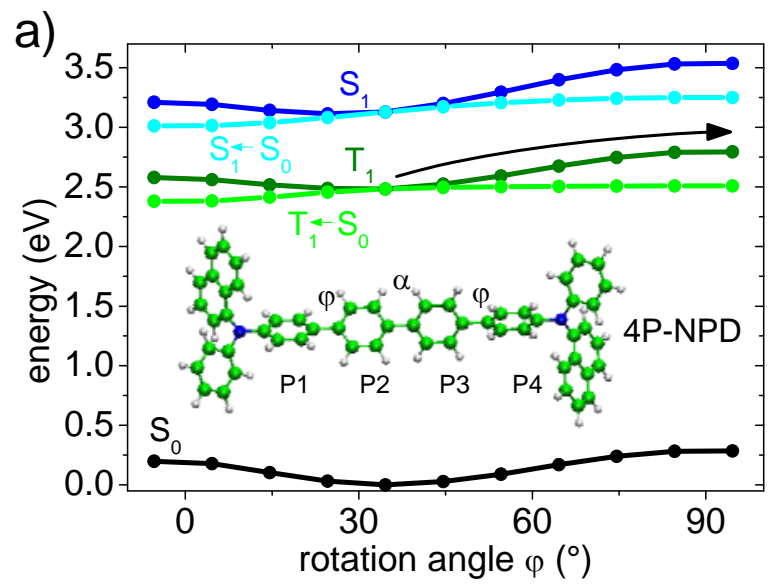

b)

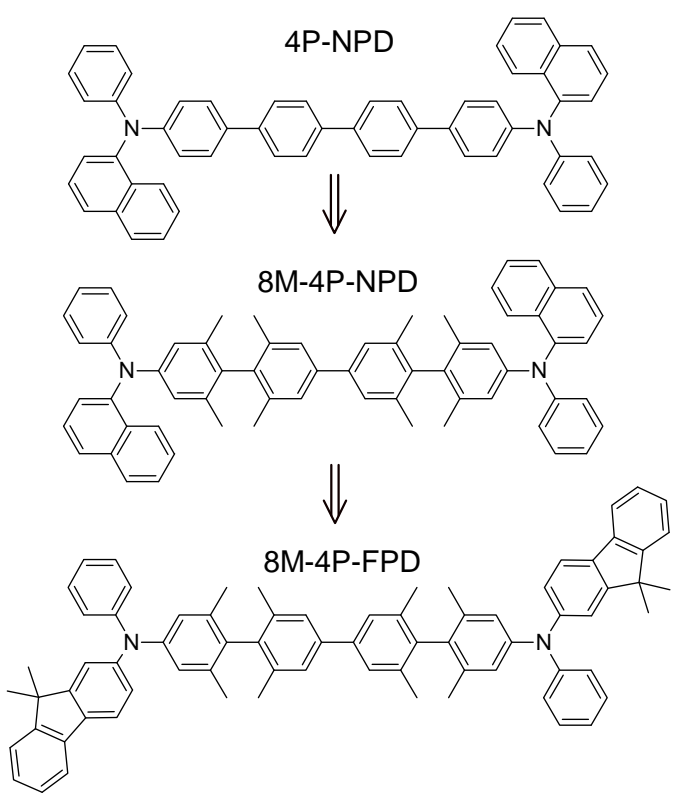

Figure 2. (a) Calculated potential surface energies and transition energies of 4P-NPD as a function of the dihedral angle $\varphi$ between the phenyl rings P1 and P2 and between P3 and P4. The dihedral angle $\alpha$ in the central biphenyl chain P2-P3 is kept at the ground state value of $\alpha=36^{\circ}$. Black: potential $S_{0}$, light green: triplet excitation energy $T_{1} \leftarrow S_{0}$, light blue: singlet excitation energy $\mathrm{S}_{1} \leftarrow \mathrm{S}_{0}$, dark green: excited triplet potential $\mathrm{T}_{1}$, dark blue: excited singlet potential $\mathrm{S}_{1}$. (b) Chemical structure of 4P-NPD, 8M-4P-NPD, and 8M-4P-FPD.
This finding is further corroborated by a geometric optimization of the 4P-NPD structure in the triplet configuration $\mathrm{T}_{1}$, which shows a substantial planarization of the quarterphenyl chain with reduced twisting angles $\alpha=4^{\circ}$ and $\varphi=16^{\circ}$. As shown in Figure 3, the planarization in the lowest triplet configuration shrinks the frontier orbitals towards the quarterphenyl core region, reducing in turn their delocalization over the terminal naphthyl and phenyl groups. This stronger localization of the frontier orbitals increases the electron-hole interaction in the relaxed $\mathrm{T}_{1}$ geometry and contributes to a further red shift of the triplet emission. A similar shrinking of the LUMO has been reported for the relaxed excited singlet geometry of another, smaller compound with a biphenyl core, the $\mathrm{N}, \mathrm{N}^{\prime}$-diphenyl-N,N'-bis(3-methylphenyl)-(1,1'-biphenyl)- 4,4'diamine (TPD) ${ }^{24}$.

The splitting between the $S_{1}$ singlet excitation and the $T_{1}$ triplet excitation of 4P-NPD depends only weakly on the dihedral angle $\varphi$ : it increases monotonously from $0.63 \mathrm{eV}$ at $\varphi=0^{\circ}$ towards $0.74 \mathrm{eV}$ at $\varphi=90^{\circ}$.

The most important result of the calculations presented in Fig. $2 \mathrm{a}$ is that an increase of the twisting angles $\varphi$ beyond $35^{\circ}$ (the angle in the optimized ground state geometry of 4P-NPD) raises the lowest triplet excitation energy. For $\varphi=90^{\circ}$ the triplet excitation energy increases by about $0.03 \mathrm{eV}$ with respect to the transition energy at $\varphi=35^{\circ}$. This indicates that compounds with large dihedral angles $\varphi$ could show triplet energies that are high enough to allow for efficient transfer to the green phosphorescent emitter $\operatorname{Ir}(\mathrm{ppy})_{2}(\mathrm{acac})$. In practice, the twisting angle $\varphi$ can be increased by introducing methyl groups to the central and peripheral phenyl rings of the quarterthphenyl chain, as shown in Fig. 2 b.

For all three compounds shown in Fig. 2b, Table 1 summarizes the geometric properties in the $\mathrm{S}_{0}$ ground state geometry and in the relaxed $\mathrm{T}_{1}$ triplet geometry, respectively. As expected, the methyl groups in 8M-4P-NPD and in 8M-4P-FPD introduce large dihedral angles between the central and the peripheral phenyl rings along the central quarterphenyl chain. As described above, 4P-NPD planarizes significantly in the relaxed $\mathrm{T}_{1}$ geometry. However, for the compounds containing methyl groups, the dihedral angles in the $T_{1}$ configuration remain at values close to the electronic ground state $S_{0}$.

Table 1. Summary of dihedral angles $\alpha$ and $\varphi$ (in degrees) of the investigated compounds in the $\mathrm{S}_{0}$ and $\mathrm{T}_{1}$ state, calculated at the B3LYP/6-31G(d) level.

\begin{tabular}{|l|l|l|l|}
\hline & $4 \mathrm{P}-\mathrm{NPD}$ & $8 \mathrm{M}-4 \mathrm{P}-\mathrm{NPD}$ & $8 \mathrm{M}-4 \mathrm{P}-\mathrm{FPD}$ \\
\hline $\mathrm{S}_{0}, \alpha$ & 36 & 37 & 38 \\
$\mathrm{~S}_{0}, \varphi$ & 35 & 89 & 89 \\
\hline $\mathrm{T}_{1}, \alpha$ & 4 & 38 & 38 \\
$\mathrm{~T}_{1}, \varphi$ & 16 & 89 & 89 \\
\hline
\end{tabular}

Detailed computational studies of 8M-4P-NPD indicate that the steric hindrance between the methyl groups enforces twisting angles of $\varphi=89^{\circ}$ in the electronic ground state $S_{0}$, with the central dihedral angle increasing only slightly to $\alpha=37^{\circ}$. The large $\varphi$ leads to a spectroscopic decoupling of the different subgroups: HOMO-1, HOMO, LUMO and LUMO+1 delocalize around the two amine groups but avoid the central bi- 
phenyl, whereas HOMO-2 and LUMO+2 localize on the biphenyl core. Enforcing $\mathrm{C}_{2}$ symmetry for $8 \mathrm{M}-4 \mathrm{P}-\mathrm{NPD}$, the orbitals HOMO and HOMO-1 differ only in a sign change between the contributions around both amine groups, with a splitting lower than $3 \mathrm{meV}$. Similar arguments apply to the nearly degenerate LUMO and LUMO+1. As will be discussed elsewhere in more detail, this allows for a symmetry breaking from $\mathrm{C}_{2}$ to $\mathrm{C}_{1}$ and a subsequent localization of HOMO and LUMO on the same terminal group of the molecule. ${ }^{25}$ This behavior is in sharp contrast to 4P-NPD where the relaxed triplet geometry still enforces a delocalization of the frontier orbitals over the entire molecule, with some shrinking of both HOMO and LUMO towards the quarterphenyl chain.
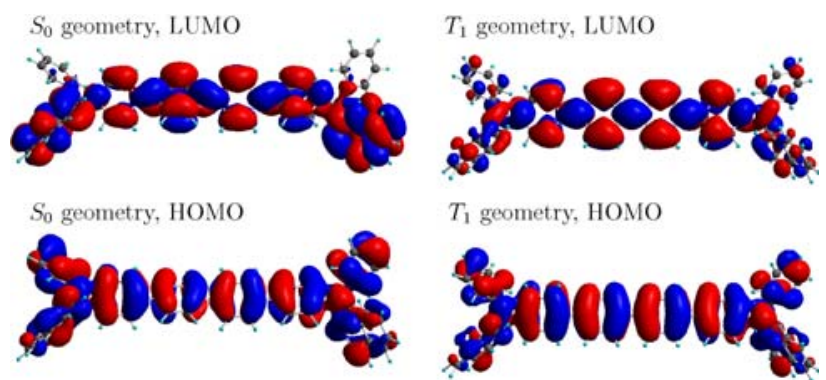

Figure 3. Frontier orbitals of 4P-NPD: HOMO (bottom) and LUMO (top), in the $\mathrm{S}_{0}$ ground state geometry (left) and in the $T_{1}$ relaxed excited geometry (right). The planarization in the $\mathrm{T}_{1}$ geometry allows both frontier orbitals to localize more strongly on the quarterphenyl chain, compare Table 1 for the respective dihedral angles between the phenyl rings.

The triplet energy can be enhanced further by adding fluorenyl side groups to the nitrogen atoms (8M-4P-FPD, Fig. 2b). As expected, the calculated singlet and triplet excitation energies of this compound remain above the respective values for 8M-4P-NPD, compare Table 4. Furthermore, these additional fluorenyl groups are expected to result in a high fluorescence yield of the material. ${ }^{26}$ Our finding that the increase in stiffness of the molecular structure raises the triplet energy agrees with previous studies of other classes of molecules. ${ }^{15,27}$

For efficient OLED operation, the HOMO and LUMO energy barriers between blocking and emissive layer need to be small to guarantee efficient charge injection and a balanced charge ratio. The HOMO and LUMO energies in 4P-NPD films are $-5.7 \mathrm{eV}^{11}$ and $-2.3 \mathrm{eV}^{11}$, respectively, which is well compatible with the blocker materials used in this study $\left(\mathrm{LUMO}_{\mathrm{BPhen}}=\right.$ $-2.9 \mathrm{eV}$ and $\mathrm{HOMO}_{\text {Spiro-TAD }}=-5.4 \mathrm{eV}$ ). As discussed in more detail in Sec. 4.2, cyclic voltammetry (CV) and DFT calculations both indicate that the increased dihedral angle leads to minor changes in the HOMO position (Table 2). Consequently, the exchange of the blue emitter should only have marginal influence on hole injection into the emitter layer.

In contrast, according to our DFT calculations, the vertical electron affinity (EA) is expected to decrease along our series (4P-NPD: 0.38 eV, 8M-4P-NPD: 0.24 eV, 8M-4P-FPD: $0.03 \mathrm{eV}$ ), indicating that electron injection from the HBL side into either 8M-4P-NPD or 8M-4P-FPD may be impeded. However, the computed values for IP and EA neglect effects arising from embedding the molecule into a polarizable medium which is expected to lead to substantial shifts. Changes of the vacuum level in molecular thin films as a result of specific morphology are also neglected. Compare Ref. 28 for details of the polarization shift, Ref. 29 for typical values of the polarization shift for molecules in the size range investigated here, and Ref. 30 for investigations of a modified vacuum level relying on UPS of molecular films. Despite possible difficulties with electron injection, we consider 4P-NPD compounds with strongly twisted phenyl rings as a promising route to increase the triplet energy and to provide $\mathrm{TH}$ by green phosphorescent emitters in OLEDs.

\section{Synthesis}

The two 4P-NPD type materials with incorporated methyl groups and different side groups were synthesized according to the route shown in Fig. 4.

The quarterphenylene synthesis started from 4,4'-diiodo2,2',6,6'-tetramethyl-1,1'-biphenyl (1). ${ }^{31}$ By using BuchwaldHartwig amination conditions the diiodo compound $\mathbf{1}$ was converted to the mono-substituted product $2 \mathbf{a}$ in $71 \%$ yield, and $\mathbf{2 b}$ in $80 \%$ yield, respectively. Using an excess of $\mathbf{1}$ suppresses the di-substitution and thus increases the yield of the desired product, compared to applying equimolar quantities. The final quarterphenylene compounds 8M-4P-NPD and 8M-4P-FPD were synthesized in dimethylformamid (DMF) by copper mediated aryl-aryl homo coupling at elevated temperatures, achieving good yields. Various temperature conditions and reaction times were applied in coupling tests with 2a, and stirring at $250^{\circ} \mathrm{C}$ for $40 \mathrm{~h}$ was found to be the most efficient procedure for selective quarterphenylene formation. Side reaction products from reductive dehalogenation were also observed, but these reaction products were not isolated due to their similar retention on silica during chromatography. Both new compounds showed good sublimation yields $(\sim 70 \%)$ and could be deposited conveniently under ultra-high vacuum atmosphere at evaporation temperatures between 240 and $280^{\circ} \mathrm{C}$.
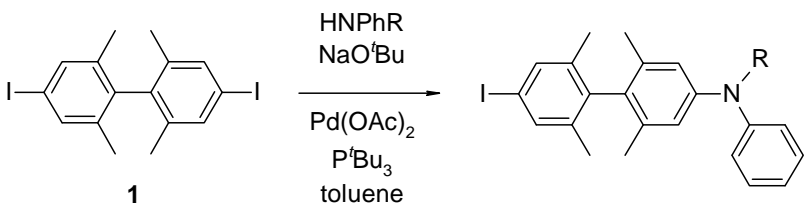

2a - naphth-1-yl (71\%)

2b - fluoren-2-yl (80\%)

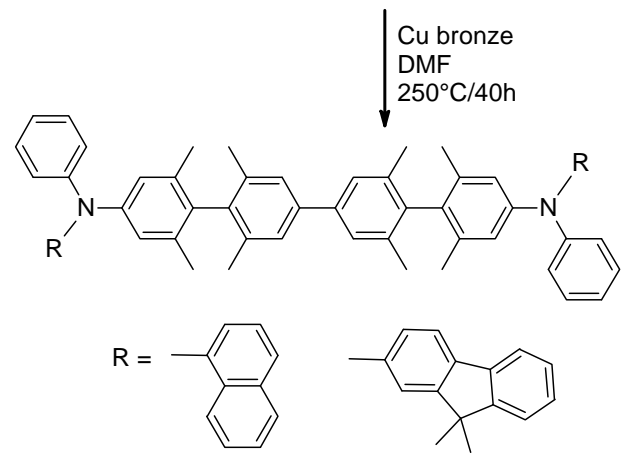

8M-4P-NPD

8M-4P-FPD

Figure 4. Synthesis route of 8M-4P-NPD and 8M-4P-FPD. 


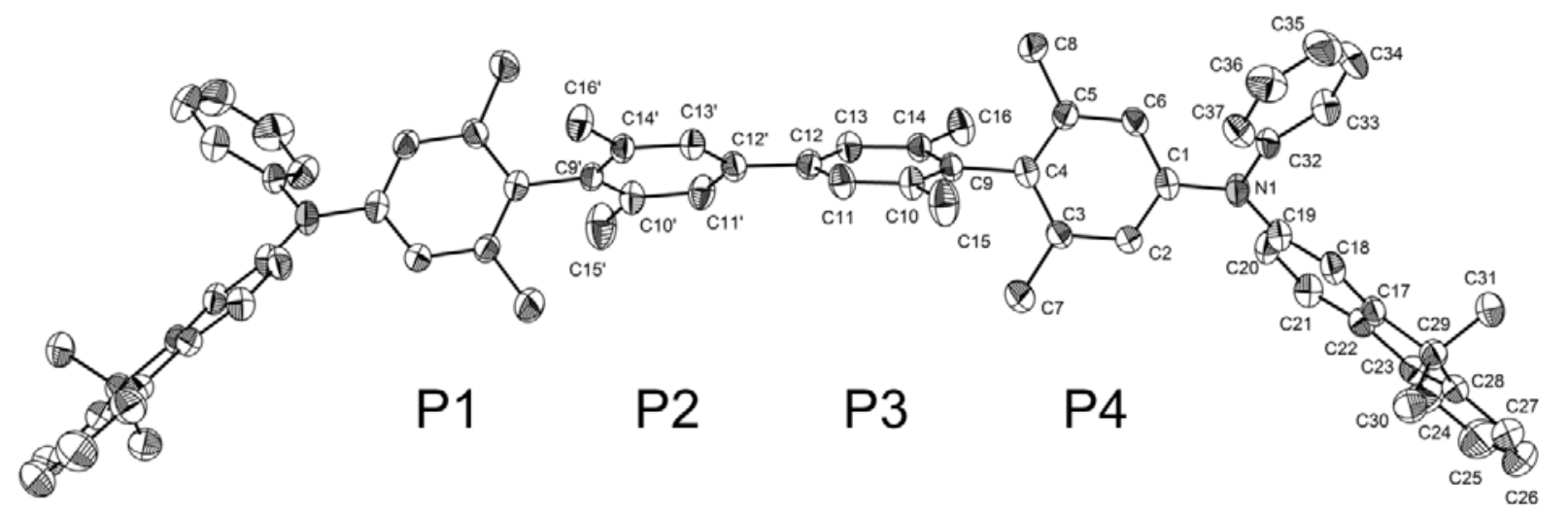

Figure 5. Crystalline structure of $8 \mathrm{M}-4 \mathrm{P}-\mathrm{FPD}$. The rotation angles $\varphi$ between the phenyl groups is $\varphi(\mathrm{P} 1 / \mathrm{P} 2)=\varphi(\mathrm{P} 3 / \mathrm{P} 4)=$ $85.37^{\circ}$

\section{Characterization}

4.1 Crystal Structure. The molecular geometry crystalline structure of $8 \mathrm{M}-4 \mathrm{P}-\mathrm{FPD}$ is derived from X-ray diffraction (XRD) measurements on 8M-4P-FPD crystals grown from toluene solution (Fig. 5).

The crystals belong to the non-centrosymmetric space group Fdd2 with $\mathrm{Z}=8$ and contain two toluene molecules per $8 \mathrm{M}-4 \mathrm{P}-\mathrm{FPD}$ unit. The orthorhombic unit cell has lattice vectors of $\mathrm{a}=56.136(1) \quad \AA, \quad \mathrm{b}=12.316(3) \quad \AA, \quad$ and $\mathrm{c}=19.762(4) \AA$.

The two halves of the 8M-4P-FPD molecule occupy symmetry equivalent positions generated by a two-fold rotation axis. The nitrogen atoms of the triarylamine system exhibit an almost trigonal planar environment indicated by the angular sum of $359.5^{\circ}$. The quarterphenylene backbone in the molecular structure of 8M-4P-FPD is not linear but slightly bent. Due to steric repulsion of the methyl groups, the relevant phenylene rings $\mathrm{P} 1$ and $\mathrm{P} 4$ are arranged orthogonally to P2 and P3 with an angle of $85.4^{\circ}$, as intended. The central biphenylene unit exhibits a rotation angle of $41^{\circ}$ between P2 and $\mathrm{P} 3$. The dihedral angles realized in the crystal structure remain close to the values computed for the free molecule, compare Table 1. This good agreement indicates that the steric hindrance introduced by the methyl groups has a larger impact on the total energy than embedding the molecule into a crystal with rather small intermolecular interactions (relying on weak van-der-Waals forces).

It was not possible to perform XRD measurements on $8 \mathrm{M}$ 4P-NPD and 4P-NPD since these compounds do not form single crystals.

4.2 Ionisation Potential. Cyclic voltammetry in dichloromethane was used to investigate the electronic properties of the quarterphenylene compounds. Within the stability window of the solvent, one reversible oxidation process was observed for both of the newly synthesized compounds and for the 4P-NPD reference (Fig. 6). The CV data and the resulting ionization potentials are summarized in Table 2 . The values are in reasonable agreement with DFT values of the ionization potential, defined as the difference between the energies of a cationic and a neutral molecule, and the respective polarization shifts deduced from the ionic radii.

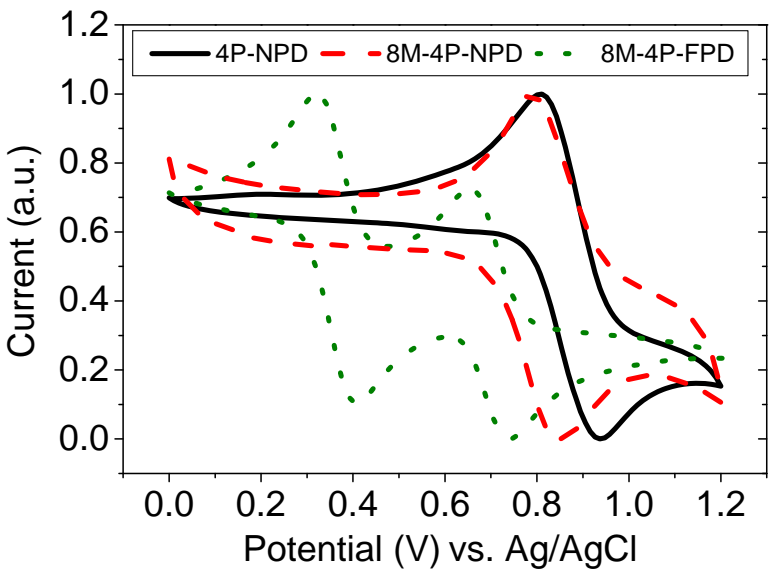

Figure 6. Cyclic voltammetry of 4P-NPD, 8M-4P-NPD and $8 \mathrm{M}-4 \mathrm{P}-\mathrm{FPD}$ with respect to a $\mathrm{Ag} / \mathrm{AgCl}$ electrode.

Table 2. Cyclo voltammetry (CV) oxidation potential in dichloromethane, derived ionization potential (IP) as determined from the $\mathrm{Fc} / \mathrm{Fc}^{+}$reference $(\mathrm{eV})$. DFT values for ionization potential IP $(\mathrm{eV})$ and HOMO level $(\mathrm{eV})$. Molecular radii $r_{\text {ion }}$ estimated assuming a density of $1.11 \mathrm{~g} / \mathrm{cm}^{3}$ (corresponding to crystalline 8M-4P-FPD). Polarization shift of IP calculated for $\mathrm{CH}_{2} \mathrm{Cl}_{2}$ (with $\varepsilon=8.93$ ), and DFT values corrected for the polarization shift, IP(B3LYP)- $\mathrm{P}_{+}$, in $\mathrm{eV}$.

\begin{tabular}{|l|l|l|l|}
\hline & 4P-NPD & $8 \mathrm{M}-4 \mathrm{P}-\mathrm{NPD}$ & $8 \mathrm{M}-4 \mathrm{P}-\mathrm{FPD}$ \\
\hline $\mathrm{CV}$ in $\mathrm{CH}_{2} \mathrm{Cl}_{2}$ & 0.88 & 0.82 & 0.70 \\
\hline $\mathrm{IP}$ in $\mathrm{CH}_{2} \mathrm{Cl}_{2}$ & 5.37 & 5.31 & 5.19 \\
\hline $\mathrm{IP}(\mathrm{B} 3 \mathrm{LYP})$ & 5.74 & 5.74 & 5.60 \\
\hline $\begin{array}{l}\mathrm{HOMO} \\
(\mathrm{B} 3 \mathrm{LYP})\end{array}$ & -4.87 & -4.92 & -4.78 \\
\hline $\mathrm{r}_{\text {ion }}(\mathrm{A})$ & 6.41 & 6.72 & 7.05 \\
\hline $\mathrm{P}_{+}(\mathrm{eV})$ & 1.00 & 0.95 & 0.91 \\
\hline IP(B3LYP)-P & 4.74 & 4.79 & 4.69 \\
\hline
\end{tabular}


An average offset of $0.55 \mathrm{eV}$ between ionization potentials based on CV measurements and on DFT calculations plus polarization shift may result from a systematic offset of our ferrocene reference, or from the assumption of embedded spherical ions when estimating the polarization shift. In summary, based on CV and on DFT, we conclude that the ionization potentials of the three model compound deviate by less than $0.2 \mathrm{eV}$ from each other, so that hole injection into the emissive layer of OLEDs comprising either of the three materials should be similar.

\subsection{Spectroscopic properties.}

Photoluminescence. Photoluminescence (PL) measurements of films consisting of our model compounds are shown in Fig. 7. The emission peaks of 4P-NPD, 8M-4P-NPD, and $8 \mathrm{M}-4 \mathrm{P}-\mathrm{FPD}$ are at $\lambda_{\max }=428 \mathrm{~nm}, 418 \mathrm{~nm}$, and $390 \mathrm{~nm}$, respectively. In the new compounds, the prominent vibronic structure observed for $4 \mathrm{P}-\mathrm{NPD}$ is blurred by a stronger broadening of each subband.

The spectral shift towards smaller wavelengths leads to a deeper blue emission color of the two new compounds compared to 4P-NPD which exhibits Commission Internationale de l'Eclairage 1931 (CIE) color coordinates of (0.158/0.074). The CIE coordinates of the new compounds show a significantly reduced y-coordinate, $(0.157 / 0.023)$ for $8 \mathrm{M}-4 \mathrm{P}-\mathrm{NPD}$ and $(0.158 / 0.021)$ for $8 \mathrm{M}-4 \mathrm{P}-\mathrm{FPD}$. This, in turn, may lead to a higher color rendering index in white OLEDs, which is important for high quality indoor lighting. However, the 8M-4P-FPD emission spectrum partly extends to below $380 \mathrm{~nm}$, making this emitter less suitable for practical applications since this part of the emission falls outside the visible range.

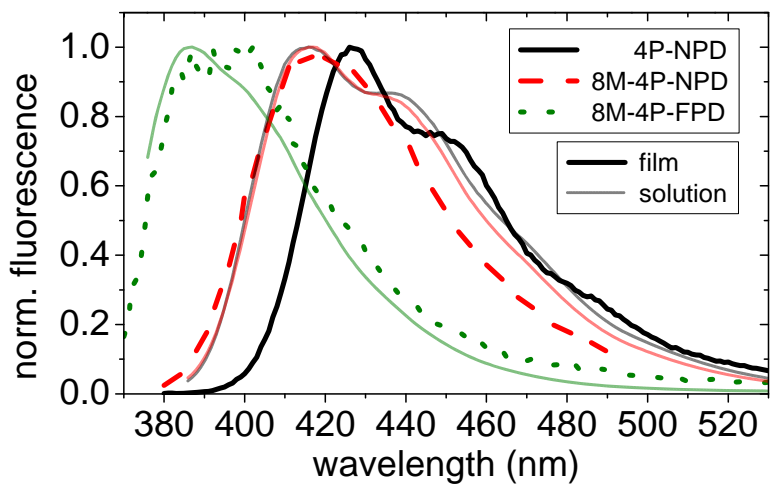

Figure 7. PL of 4P-NPD, 8M-4P-NPD, and 8M-4P-FPD thin film and in toluene solution.

Both new compounds show only small spectral deviations between their emission in thin film and in toluene solution, indicating no significant molecular interaction between the molecules even when densely packed. In contrast, the thin film spectra of 4P-NPD are red-shifted by about $10 \mathrm{~nm}$ with respect to the solution spectra. This difference in peak emission and the broadening of the solution spectrum are attributed to a larger influence of the surroundings onto 4P-NPD with the more flexible central quarterphenyl chain, allowing for strong elongations of low-frequency torsional modes.

Furthermore, we have measured the photoluminescence quantum yield (PL-QY) of thin films of 4P-NPD, $8 \mathrm{M}-4 \mathrm{P}-\mathrm{NPD}$, and $8 \mathrm{M}-4 \mathrm{P}-\mathrm{FPD}$ to be $41 \pm 13 \%, 42 \pm 13 \%$, and $14 \pm 4 \%$, respectively. Apparently, 8M-4P-NPD can be as efficient as 4P-NPD when used as a bulk emitter within an OLED structure. The low PL-QY of 8M-4P-FPD is not understood so far because the additional fluorenyl groups were expected to increase the fluorescence yield.

Phosphorescence. To achieve TH in OLEDs, the position of the triplet level of the blue emitter is crucial. The triplet energies of all studied compounds are derived from gated PL measurements of thin films at low temperature (Fig. 8). For 8M-4P-NPD and 8M-4P-FPD, the entire fluorescence spectra are shifted towards smaller wavelengths, indicating that also the triplet state should occur at a higher energy than in 4P-NPD. In comparison with 4P-NPD, the phosphorescence spectra of the two new compounds are broadened (cf. Fig. 7). The emission peaks lie at $566 \mathrm{~nm}, 546 \mathrm{~nm}$, and $519 \mathrm{~nm}$ for 4P-NPD, 8M-4P-NPD, and 8M-4P-FPD, respectively.

The phosphorescence peak wavelength $566 \mathrm{~nm}$ of 4P-NPD obtained within this work is considerably higher than the value of $539 \mathrm{~nm}$ measured by Schwartz et al. ${ }^{11}$ Schwartz et al. doped 4P-NPD into a polystyrene matrix, while in this work a neat film is used. Two reasons may account for the substantial difference between the phosphorescence peaks obtained using these two methods: interactions with the polystyrene, or different relaxation dynamics in the triplet density of states. Note that triplet energies reported elsewhere show similar deviations. For example, for the well-known material N,N'-di(naphthalene-1-yl)-N,N'-diphenyl-benzidine (NPD), which chemically differs from 4P-NPD by just two phenyl rings, values within the range between $514 \mathrm{~nm}$ and $563 \mathrm{~nm}$ have been reported. ${ }^{13,32,33}$

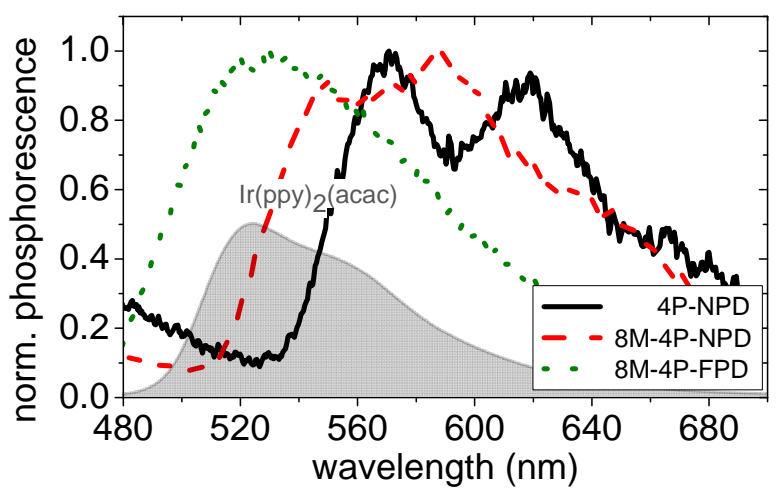

Figure 8. Phosphorescence spectra at low temperature $(<100 \mathrm{~K})$, obtained on thin films of 4P-NPD, $8 \mathrm{M}-4 \mathrm{P}-\mathrm{NPD}$, and 8M-4P-FPD, respectively. The PL spectrum of $\operatorname{Ir}(\mathrm{ppy})_{2}(\mathrm{acac})$ at ambient temperature is shown for comparison (grey curve).

For 8M-4P-NPD and 8M-4P-FPD, both the fluorescence and the phosphorescence spectra are shifted towards shorter wavelengths with respect to $4 \mathrm{P}-\mathrm{NPD}$, indicating that TH by 
an efficient green phosphorescent emitter like $\operatorname{Ir}(\mathrm{ppy})_{2}(\mathrm{acac})$ should be within reach.

Analysis of observed line shapes. For a meaningful comparison between the average emission energies of different molecules, the observed emission spectra $I(\lambda)$ have to be reported as a function of energy in the form $\mathrm{I}(\mathrm{E}) \propto \mathrm{I}(\lambda) / \mathrm{E}^{2}$. Moreover, the proportionality of the emission intensity $\mathrm{I}(\mathrm{E})$ to the density of photons scales as $\mathrm{E}^{3}$, requiring a further division by $\mathrm{E}^{3}$ before the underlying molecular properties emerge. ${ }^{34}$ Hence, the vertical transition energy from the relaxed excited geometry of a molecule can be determined by averaging over the observed emission intensity, rescaled as $\mathrm{I}(\mathrm{E}) / \mathrm{E}^{3} \propto \mathrm{I}(\lambda) / \mathrm{E}^{5}$. This allows for a direct comparison with calculated transition energies.

In practice, the rescaled emission intensity $\mathrm{I}(\mathrm{E}) / \mathrm{E}^{3}$ is fitted to a Poisson progression over an effective internal mode $\hbar \omega$ with transition probabilities:

$$
P_{n}(S)=e^{-S} S^{n} / n !
$$

towards the $n$-th vibrational level in the ground state potential, including a different Gaussian broadening for each subband. This allows to define the vertical transition energy $E_{\text {vert }}=E_{00}-S \hbar \omega$ of either phosphorescence or fluorescence, where $E_{00}$ is the apparent origin of the emission spectrum, and S its Huang-Rhys factor serving as the argument of the Poisson progression. The data is summarized in Table 3. This procedure provides meaningful values for the vertical transition energies $T_{1} \rightarrow S_{0}$ and $S_{1} \rightarrow S_{0}$, even in cases where the long wavelength part of the emission spectra extends beyond the detection window.

Table 3: Phosphorescence line shapes analyzed in terms of a Poisson progression over an effective internal vibration according to Eq. (1); see text for further details.

\begin{tabular}{|l|l|l|l|}
\hline & 4 P-NPD & $8 \mathrm{M}-4 \mathrm{P}-\mathrm{NPD}$ & $8 \mathrm{M}-4 \mathrm{P}-\mathrm{FPD}$ \\
\hline $\mathrm{E}_{00}(\mathrm{eV})$ & 2.17 & 2.26 & 2.41 \\
\hline$\hbar \omega_{\text {eff }}(\mathrm{eV})$ & 0.170 & 0.168 & 0.161 \\
\hline $\mathrm{S}_{\text {eff }}$ & 1.56 & 1.71 & 1.60 \\
\hline $\begin{array}{l}\mathrm{T}_{1} \rightarrow \mathrm{S}_{0}= \\
\mathrm{E}_{\text {vert }}(\mathrm{eV})\end{array}$ & 1.91 & 1.98 & 2.15 \\
\hline $\mathrm{E}_{\mathrm{ph}}(\mathrm{eV})$ & 1.98 & 2.05 & 2.22 \\
\hline
\end{tabular}

The vertical transition energies defined in this way reveal that the observed splitting $\Delta_{\mathrm{ST}}$ between the PL transition $\mathrm{S}_{1} \rightarrow \mathrm{S}_{0}\left(\mathrm{~S}_{1}\right)$ and the phosphorescence transition $\mathrm{T}_{1} \rightarrow \mathrm{S}_{0}\left(\mathrm{~T}_{1}\right)$ increases from $0.77 \mathrm{eV}$ for 4P-NPD to $0.83 \mathrm{eV}$ for 8M-4P-NPD and $0.85 \mathrm{eV}$ for $8 \mathrm{M}-4 \mathrm{P}-\mathrm{FDP}$ (Table 4). Due to the definition of each transition energy relying on an average over the rescaled emission spectrum, for 4P-NPD the singlettriplet splitting $\Delta_{\mathrm{ST}}=0.77 \mathrm{eV}$ does not match the previous estimate of $0.61 \mathrm{eV}$ deduced from the peak wavelengths ${ }^{11}$.

The calculated and observed values for the Stokes shift between absorption, $\mathrm{S}_{1} \leftarrow \mathrm{S}_{0} \quad\left(\mathrm{~S}_{0}\right)$, and phosphorescence, $\mathrm{T}_{1} \rightarrow \mathrm{S}_{0}\left(\mathrm{~T}_{1}\right)$, compare favorably. The last two lines of Table 4 give the difference either between calculated and measured absorption energies, or between calculated and measured phosphorescence bands. For the three model compounds, TD-DFT on average underestimates the observed vertical transition energies by $0.16 \mathrm{eV}$.

For 4P-NPD, the $\mathrm{S}_{1}$ singlet excitation in the $\mathrm{S}_{0}$ geometry resulting from the TD-DFT calculation amounts to $3.13 \mathrm{eV}$. The $T_{1}$ triplet emission from the optimized $T_{1}$ geometry has an energy of $1.71 \mathrm{eV}$, resulting in a calculated Stokes shift of $1.42 \mathrm{eV}$ between the lowest absorption band and the average phosphorescence. This value is in excellent agreement with the measured energy difference of $1.43 \mathrm{eV}$. When comparing the lowest measured absorption band and the phosphorescence spectra for all three compounds, the Stokes shift is on average $1.42 \mathrm{eV}$, again in very good agreement with the calculated value of $1.44 \mathrm{eV}$. This indicates that the energy difference between the lowest absorption band and the phosphorescence energy can be reproduced quite precisely with TD-DFT.

Table 4. Summary of observed and calculated molecular transition energies, in $\mathrm{eV}$. The starting electronic configuration and relaxed geometry before the transition occurs is given in parentheses. All calculated TD-DFT transition energies rely either on the relaxed $\mathrm{S}_{0}$ geometry or the relaxed $\mathrm{T}_{1}$ geometry.

\begin{tabular}{|l|l|l|l|l|}
\hline & $\begin{array}{l}4 \mathrm{P}- \\
\text { NPD }\end{array}$ & $\begin{array}{l}8 \mathrm{M}-4 \mathrm{P}- \\
\text { NPD }\end{array}$ & $\begin{array}{l}8 \mathrm{M}-4 \mathrm{P}- \\
\text { FPD }\end{array}$ & $\begin{array}{l}\operatorname{Ir}(\text { ppy })_{2} \\
(\mathrm{acac})\end{array}$ \\
\hline calc. & & & & \\
$\mathrm{S}_{1} \leftarrow \mathrm{S}_{0}\left(\mathrm{~S}_{0}\right)$ & 3.13 & 3.21 & 3.49 & 2.77 \\
$\mathrm{~T}_{1} \rightarrow \mathrm{S}_{0}\left(\mathrm{~T}_{1}\right)$ & 1.71 & 1.74 & 2.06 & 2.18 \\
\hline exp. & & & & \\
$\mathrm{S}_{1} \leftarrow \mathrm{S}_{0}\left(\mathrm{~S}_{0}\right)$ & 3.34 & 3.44 & 3.51 & \\
$\mathrm{~S}_{1} \rightarrow \mathrm{S}_{0}\left(\mathrm{~S}_{1}\right)$ & 2.68 & 2.81 & 3.00 & \\
$\mathrm{~T}_{1} \rightarrow \mathrm{S}_{0}\left(\mathrm{~T}_{1}\right)$ & 1.91 & 1.98 & 2.15 & 2.21 \\
\hline calc. & & & & \\
$\mathrm{S}_{1} \leftarrow \mathrm{S}_{0}\left(\mathrm{~S}_{0}\right)-$ & 1.42 & 1.47 & 1.43 & 0.59 \\
$\mathrm{~T}_{1} \rightarrow \mathrm{S}_{0}\left(\mathrm{~T}_{1}\right)$ & & & & \\
\hline $\exp$. & & & & \\
$\mathrm{S}_{1} \leftarrow \mathrm{S}_{0}\left(\mathrm{~S}_{0}\right)-$ & 1.43 & 1.46 & 1.36 & \\
$\mathrm{~T}_{1} \rightarrow \mathrm{S}_{0}\left(\mathrm{~T}_{1}\right)$ & & & & \\
\hline $\exp . \Delta_{\mathrm{ST}}$ & & & & \\
$\mathrm{S}_{1} \rightarrow \mathrm{S}_{0}\left(\mathrm{~S}_{1}\right)-$ & 0.77 & 0.83 & 0.85 & \\
$\mathrm{~T}_{1} \rightarrow \mathrm{S}_{0}\left(\mathrm{~T}_{1}\right)$ & & & & \\
\hline calc-exp & & & & \\
$\mathrm{S}_{1} \leftarrow \mathrm{S}_{0}\left(\mathrm{~S}_{0}\right)$ & -0.21 & -0.23 & -0.02 & \\
\hline calc-exp & & & & \\
$\mathrm{T}_{1} \rightarrow \mathrm{S}_{0}\left(\mathrm{~T}_{1}\right)$ & -0.19 & -0.24 & -0.09 & -0.03 \\
\hline
\end{tabular}

\section{Blue OLEDs}

To investigate the new materials and, further, to test their potential as blue fluorescent bulk emitters, we fabricated OLEDs with the structures shown in Fig. 9a. The transport 
a)

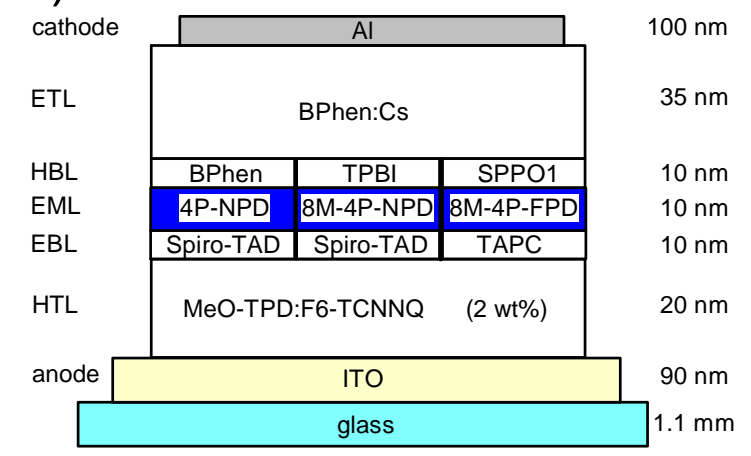

c)

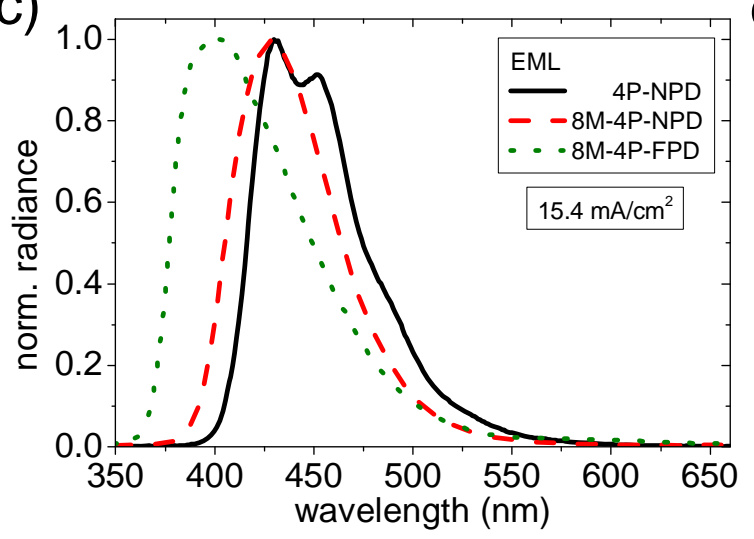

b)

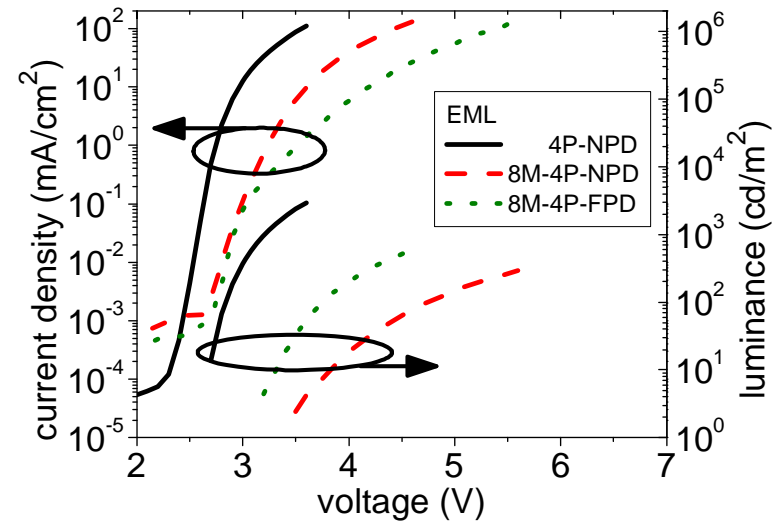

d)

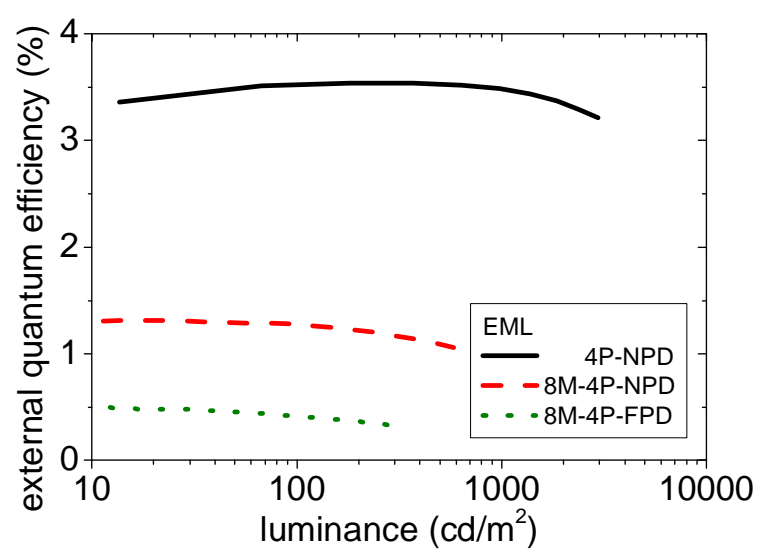

Figure 9. (a) Layer architecture, (b) IVL-characteristics, (c) spectral radiance, and (d) EQE of the OLEDs comprising 4P-NPD, 8M-4P-NPD, and 8M-4P-FPD as EMLs.

layer thickness is identical for all three OLEDs to ensure optical comparability. Different blocker materials are applied to the different emitters since these were found to provide superior performance than 4,7-diphenyl-1,10-phenanthroline (BPhen) or 2,2',7,7'-tetrakis-(N,N-diphenylamino)-9,9'spirobifluorene (Spiro-TAD) which are typically used in combination with 4P-NPD. ${ }^{12,20,22}$

Compared to the 4P-NPD based OLED, the new compounds show a much flatter current-voltage-luminance (IVL) characteristic (Fig. 9b), which may result from energy barriers between the different layers and a charge imbalance. This is in good agreement with the fact that luminance sets in at higher voltages for 8M-4P-NPD and 8M-4P-FPD than for 4P-NPD. Figure 9c shows the normalized spectral emission of our OLEDs (at a current density of $15.4 \mathrm{~mA} \mathrm{~cm}^{-2}$ ). These spectra correlate with the PL measurements (cf. Fig. 7) confirming that the emission results from the respective emitter material and not from any of the blocking layers. However, the EQE of the OLEDs comprising the new compounds is strongly reduced compared to the 4P-NPD OLED (Fig. 9d). The maximum EQEs for 8M-4P-NPD and 8M-4P-FPD OLEDs are $1.3 \%$ and $0.5 \%$, respectively. This efficiency drop mainly results from the higher LUMO energy of the new materials, which hinders electron injection and leads to a deterioration of the charge balance. In the case of 8M-4P-FPD, the lower $\mathrm{PL}-\mathrm{QY}$ is an additional reason for the reduced EQE.

\section{TH in OLEDs}

6.1 8M-4P-NPD. As previously discussed, it is expected that the triplet energy of 8M-4P-NPD is too low to allow efficient triplet harvesting by green phosphors. Nevertheless, a test series of TH OLEDs is fabricated. Figure 10a shows a proposed energy scheme of the EML and the surrounding blocking layers. It is assumed that the exciton generation zone, like in the case of $4 \mathrm{P}-\mathrm{NPD}$, is close to the HBL interface, here TPBI, so that triplets can diffuse towards the phosphorescent emitter, which is doped into 8M-4P-NPD at the other side of the EML. Additionally, we vary the intrinsic layer thickness of 8M-4P-NPD between 3 and $9 \mathrm{~nm}$, which corresponds to the distance $x$ between exciton generation zone and $\mathrm{TH}$ zone. In this experiment, the phosphorescent emitter $\operatorname{Ir}(\mathrm{ppy})_{2}(\mathrm{acac})$ is doped into the emitter to harvest triplets.

To avoid triplet quenching at the electron blocking layer, the triplet level of Spiro-TAD needs to be higher than that of $\operatorname{Ir}(\text { ppy })_{2}(\mathrm{acac})$. Since Spiro-TAD is typically used as blocker material for green OLEDs, we assume that the triplet energy is sufficiently high. To the best of our knowledge, the triplet energy of Spiro-TAD was never determined experimentally. The current-voltage (IV) characteristics are slightly dependent on the 8M-4P-NPD intrinsic layer thickness $x$ (Fig. 10b); the thicker the layer, the flatter the IV curve. This results from the higher voltage drop over the intrinsic layer. 
More importantly, the luminance is strongly increased by a decrease of $x$. This is accompanied by a change in the emission spectra (Fig. 10c), where the green emission, which dominates the luminance, increases with decreasing $x$. This emission increase indicates typical TH behavior: Due to the diffusion of triplets away from the exciton generation interface and the corresponding exponential decrease of the number of triplets with larger $x$, a small distance between exciton generation zone and $\mathrm{TH}$ zone is most beneficial for triplet harvesting. However, at the same time, the decrease of layer thickness $x$ leads to a loss in blue 8M-4P-NPD emission due to singlet transfer from $8 \mathrm{M}-4 \mathrm{P}-\mathrm{NPD}$ to $\operatorname{Ir}(\mathrm{ppy})_{2}$ (acac). Here, singlets are converted into triplets due to the high intersystem crossing rate of $\operatorname{Ir}(\mathrm{ppy})_{2}(\mathrm{acac})$ and additionally contribute to the green emission.

The decrease in blue emission and increase in green emission with increasing layer thickness $x$ confirms the assumption that the exciton generation zone is next to the HBL. With increasing applied voltage the blue emission peak grows considerably faster than the green emission, leading to a pronounced voltage-dependence of the electroluminescence spectra. This behavior is typical for white TH OLEDs, as the exciton density on phosphorescent emitters is higher than on the fluorescent emitter; their emission thus is more prone to bimolecular quenching.

At low luminance, the EQE of the TH OLEDs (Fig. 10d) is improved by more than a factor of 2 compared to the previously discussed blue 8M-4P-NPD OLEDs ( $c f$. Fig. 9d).
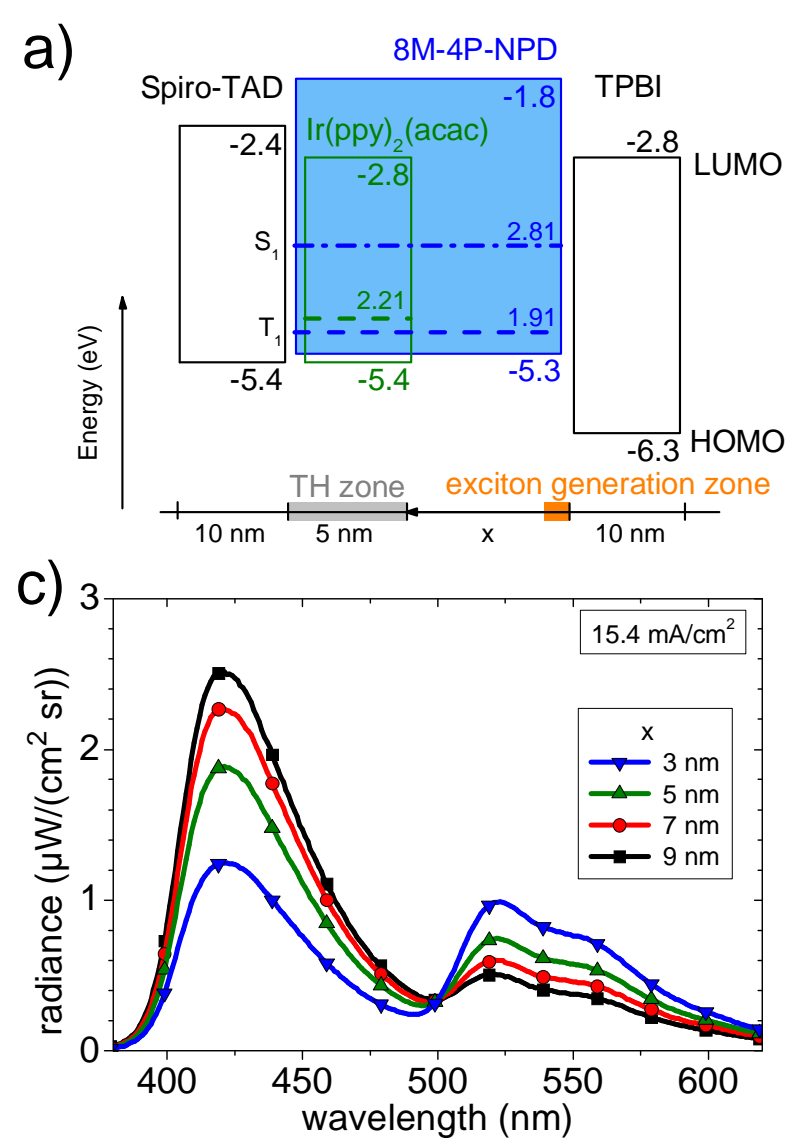

These results suggest that $\operatorname{Ir}(\mathrm{ppy})_{2}$ (acac) emission is caused by $\mathrm{TH}$, while contributions resulting from direct recombination and singlet transfer (at small distances) cannot be fully excluded. This is interesting considering that according to Table 4, the triplet transition of 8M-4P-NPD lies $0.23 \mathrm{eV}$ below that of $\operatorname{Ir}(\mathrm{ppy})_{2}(\mathrm{acac})$. One possible explanation for this behavior is that the 8M-4P-NPD phosphorescence sets in at $509 \mathrm{~nm}$ ( $c f$. Fig. 8), implying that the fraction of triplets at the high energy end of the density of states transfer to the triplet level of $\operatorname{Ir}(\mathrm{ppy})_{2}$ (acac), where they decay radiatively.

However, the blue reference OLEDs cannot provide an EQE above $1.3 \%$, which limits the overall EQE of the 8M-4P-NPD TH OLEDs. For comparison, OLEDs with only $4 \mathrm{P}-\mathrm{NPD}$ as emitter achieve EQE values in the range of $4 \%{ }^{23}$. Since 4P-NPD and 8M-4P-NPD have a similar PL-QY, we assume that the difference in EQE is caused by the hindered electron injection into 8M-4P-NPD: The LUMO energy of 8M-4P-NPD of $-1.8 \mathrm{eV}$ provides a high energy barrier for electrons to the HBL TPBI of $-1.0 \mathrm{eV}$.

6.2 8M-4P-FPD. A similar series of devices was studied for the other blue emitter 8M-4P-FPD. Figure 11 illustrates the performance of the TH OLEDs based on 8M-4P-FPD, with a distance variation of $x=3,5$, and $7 \mathrm{~nm}$. In comparison to 8M-4P-NPD, we find the same trends in IVL behavior (Fig. 11b), spectral emission (Fig. 11c) and EQE (Fig. 11d) upon increasing $x$. However, the contribution of $\operatorname{Ir}(\mathrm{ppy})_{2}(\mathrm{acac})$ emission to the spectrum is much higher compared to the case of $8 \mathrm{M}-4 \mathrm{P}-\mathrm{NPD}$.

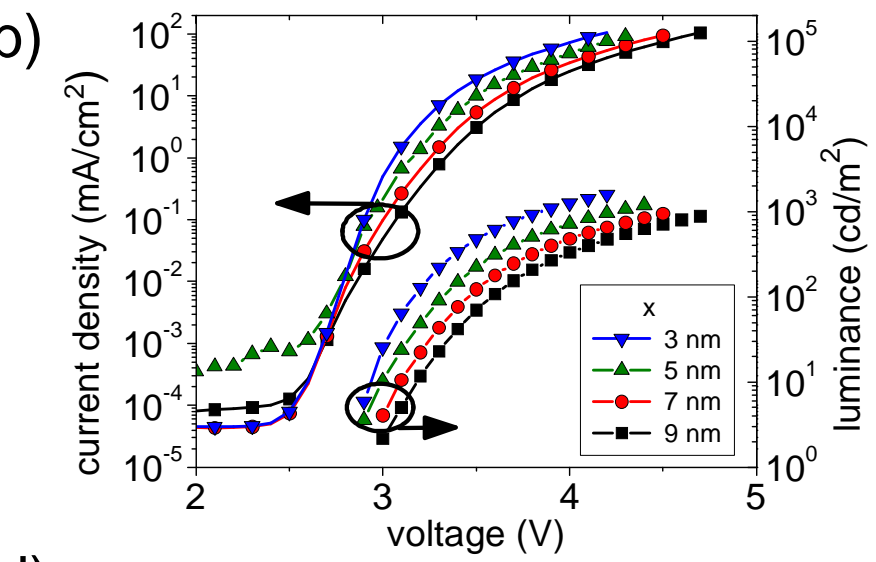

d)

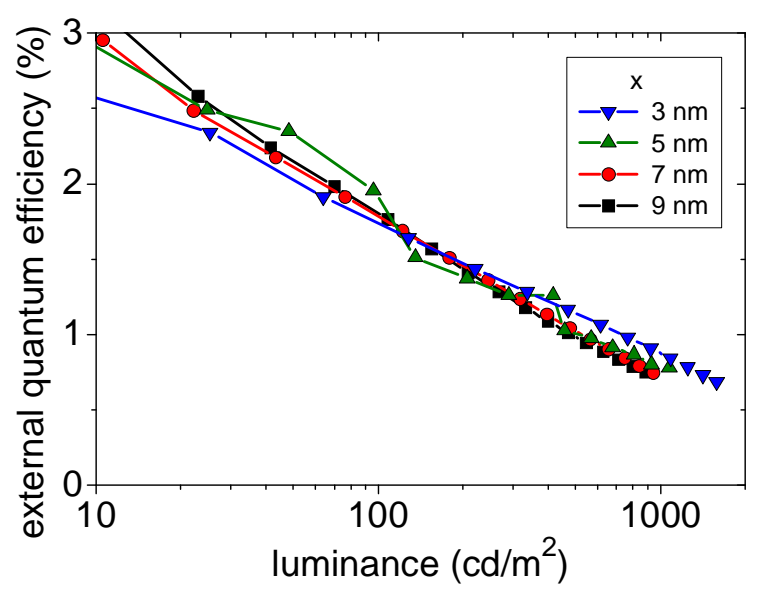

Figure 10. (a) Energy scheme, (b) IVL-characteristics, (c) spectral radiance, and (d) EQE of the 8M-4P-NPD TH OLEDs 
a)

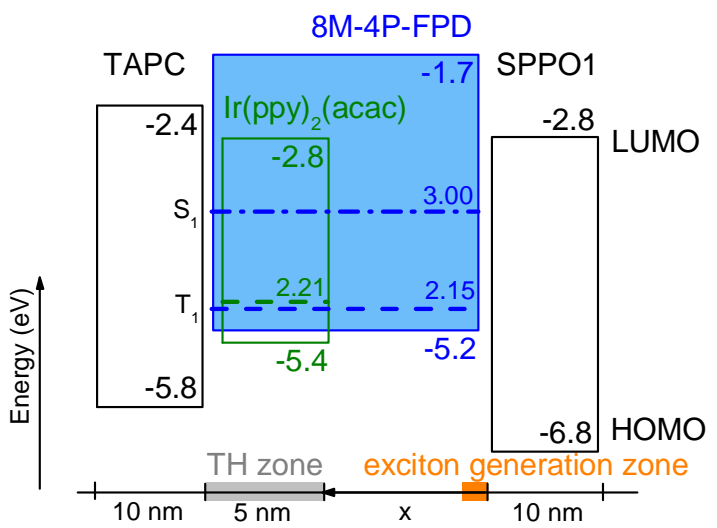

c)

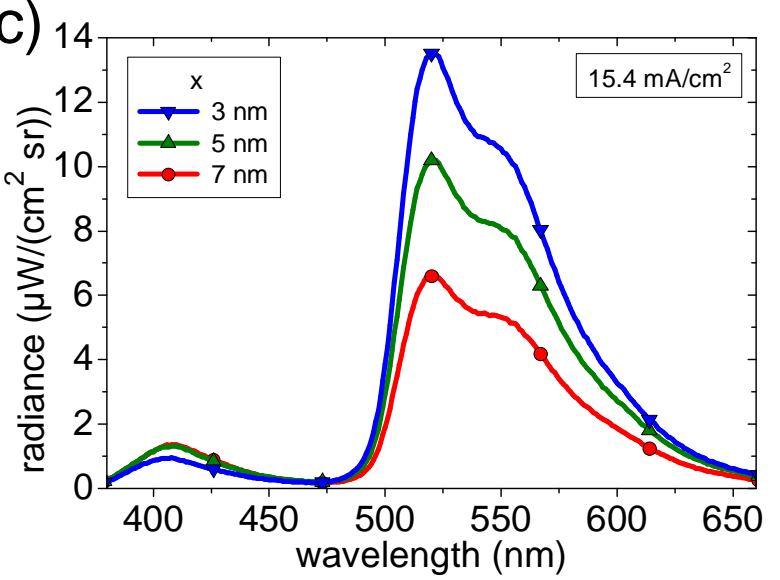

b)

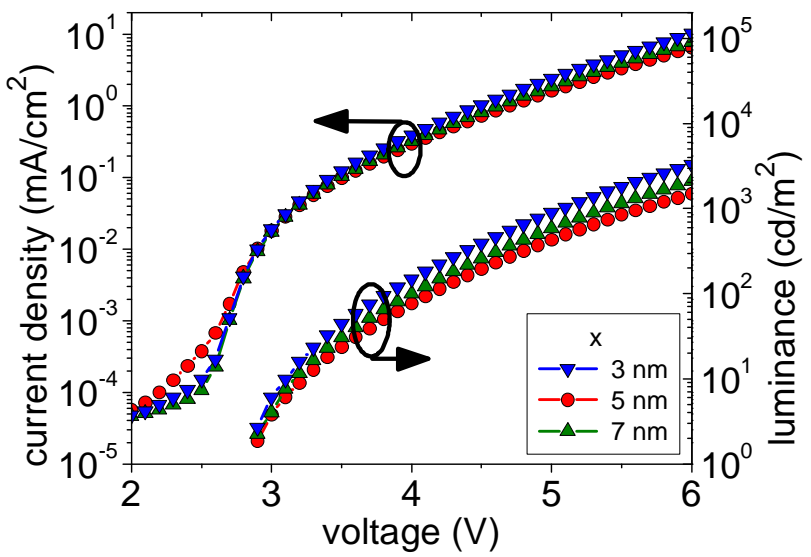

d)

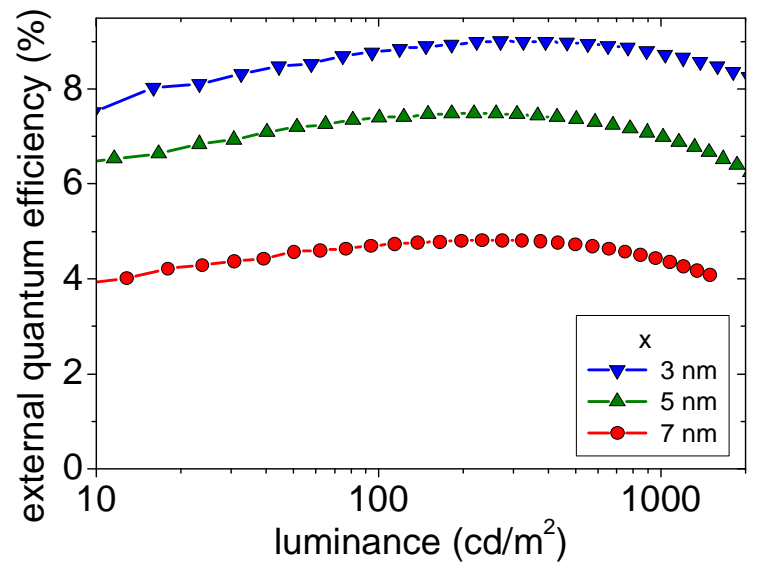

Figure 11. (a) Energy scheme, (b) IVL-characteristics, (c) spectral radiance, and (d) EQE of the 8M-4P-FPD TH OLEDs

This is in good agreement with the fact that due to the higher triplet energy of 8M-4P-FPD, a larger fraction of triplets can be transferred to $\operatorname{Ir}(\mathrm{ppy})_{2}$ (acac). Singlet exciton transfer is only observed for small distances $x$ like in case of $8 \mathrm{M}-4 \mathrm{P}-\mathrm{NPD}$, reducing in turn the blue singlet emission, e.g. for $\mathrm{x}=3 \mathrm{~nm}$.

For the TH OLED with $3 \mathrm{~nm}$ intrinsic $8 \mathrm{M}-4 \mathrm{P}-\mathrm{FPD}$ thickness, the EQE approaches $9 \%$. Despite the apparent high efficiency of $\mathrm{TH}$ from $8 \mathrm{M}-4 \mathrm{P}-\mathrm{FPD}$, the blue emission remains rather weak. Again, the high LUMO energy of $-1.7 \mathrm{eV}$ hinders the efficient electron injection into 8M-4P-FPD, thus preventing a balanced distribution of holes and electrons.

\section{Summary and Conclusions}

In summary, we developed two blue fluorescent bulk emitters with high triplet energies to facilitate triplet harvesting by green phosphorescent emitters. Chemical engineering was based on small changes of the structure of 4P-NPD: Quantum chemical calculations indicate that an increase in triplet energy occurs by increasing the rotation angle of the outer phenyl rings (8M-4P-NPD), and, further, by the incorporation of fluorenyl side groups (8M-4P-FPD). This prediction was verified experimentally by measuring and analyzing the phosphorescence spectra of 4P-NPD, 8M-4P-NPD, and 8M-4P-FPD. Vertical transition energies for the $\mathrm{T}_{1} \rightarrow \mathrm{S}_{0}$ transition as high as $2.15 \mathrm{eV}$ were observed for 8M-4P-FPD.
The two new compounds 8M-4P-NPD and 8M-4P-FPD are implemented as blue bulk emitters into OLEDs. A maximum EQE of $1.3 \%$ and $0.5 \%$, is observed for $8 \mathrm{M}-4 \mathrm{P}-\mathrm{NPD}$ and $8 \mathrm{M}-$ 4P-FPD, respectively. This is considerably lower than the $3.4 \%$ reached by $4 \mathrm{P}-\mathrm{NPD}$ due to the high LUMO levels of the new compounds, which impede electron injection and lead to charge imbalance as well as high driving voltages. To overcome the issue of electron injection, additional electron withdrawing groups at the molecule (such as bromide) might be helpful to shift the HOMO and LUMO level towards lower energies, while maintaining the triplet energy. Thereby, charge carrier balance and OLED efficiencies can be improved. ${ }^{15}$

Finally, we demonstrated triplet harvesting by the green phosphorescent emitter $\operatorname{Ir}(\mathrm{ppy})_{2}$ (acac) for both new compounds. A maximum of $9 \%$ EQE was obtained for the blue-green TH OLED comprising 8M-4P-FPD, which is basically limited by the efficiency of the blue emitter. However, our energy considerations using peak wavelength or average energy of the phosphorescence spectrum cannot entirely explain $\mathrm{TH}$ by the green emitter. Nevertheless, this research provides a useful strategy for engineering new blue bulk emitters that are suitable for triplet harvesting with green phosphors. 


\section{Experimental Details}

General remarks: Buchwald-Hartwig amination reactions were carried out using the standard Schlenk-technique under nitrogen. Commercially available reagents and solvents were used as received. Extra dry toluene over molecular sieve was purchased from Acros. Tri-tert-butylphosphine (abcr GmbH, Germany) was diluted with dry toluene to obtain a solution with a concentration of $1 \mathrm{~mol} \mathrm{~L}^{-1}$. The C-C coupling in $N, N$ dimethylformamide (for analysis, AppliChem $\mathrm{GmbH}$ ) was performed in an Ace Glass pressure tube with copper bronze, which was activated with sodium EDTA and stored under nitrogen atmosphere. ${ }^{1} \mathrm{H}$ and ${ }^{13} \mathrm{C}$ NMR spectra were recorded at $25^{\circ} \mathrm{C}$ with a Bruker DRX $500 \mathrm{P}$ instrument at 500.13 and $125.76 \mathrm{MHz}$, respectively. The assignment of quaternary $\mathrm{C}$, $\mathrm{CH}, \mathrm{CH}_{2}$, and $\mathrm{CH}_{3}$ was completed using DEPT spectra. Elemental analyses were achieved with a Eurovektor Hekatech EA-3000 elemental analyzer. All mass spectra were recorded with a Bruker Esquire-LC 00084 instrument.

The quarterphenylene compounds were purified in vacuum using a gradient sublimation device, purchased from CreaPhys $\mathrm{GmbH}$, Dresden. The sublimation yield given for the quarterphenylene compounds is the overall yield of two sublimations.

9,9-Dimethyl- $\mathrm{N}$-phenyl-9H-fluoren-2-amine: In a flame dried Schlenk-flask 2-bromo-9,9-dimethyl-9H-fluoren (11.63 g, $42.57 \mathrm{mmol})$ and palladium(II)acetate $(287 \mathrm{mg}, 1.28 \mathrm{mmol}$, $3 \mathrm{~mol} \%$ ) were dissolved in dry toluene $(250 \mathrm{~mL}) .{ }^{35}$ After addition of tri-tert-butylphosphine solution in toluene $(6.4 \mathrm{~mL}, 1$ mol L ${ }^{-1}, 6.4 \mathrm{mmol}, 15 \mathrm{~mol} \%$ ) the color turned from yellow to orange and the solution was further stirred. During $15 \mathrm{~min}$ the color disappears and sodium tert-butoxide $(6.1 \mathrm{~g}, 63.48 \mathrm{mmol}$, $150 \mathrm{~mol} \%$ ) were added in one portion, followed by aniline $(7.8 \mathrm{~mL}, 85.43 \mathrm{mmol})$. The mixture was heated in an oil bath $\left(105^{\circ} \mathrm{C}\right)$ while stirring overnight. The white precipitate was filtered off with a Büchner funnel and the solvent was removed with a rotary evaporator and dried in vacuum. Column chromatography with cyclohexane/toluene $(1: 1)$ and silica (K60) was applied for purification. The product $\left(\mathrm{R}_{\mathrm{f}}=0.52\right)$ was isolated as a colorless solid (10.94 g, $38.33 \mathrm{mmol}, 90 \%)$.

m.p. $107{ }^{\circ} \mathrm{C} . \mathrm{C}_{21} \mathrm{H}_{19} \mathrm{~N}\left(285.38 \mathrm{~g} \mathrm{~mol}^{-1}\right)$ : calcd. (\%) C 88.38, H 6.71, N 4.91; found: $\mathrm{C} 88.59, \mathrm{H}$ 6.71, $\mathrm{N} 4.91 .{ }^{1} \mathrm{H}$ NMR $\left(\mathrm{CDCl}_{3}, 500 \mathrm{MHz}\right) \delta(\mathrm{ppm}): 7.61\left(\mathrm{br} \mathrm{m}, 2 \mathrm{H}, \mathrm{H}_{\mathrm{ar}}\right), 7.39$ (d, ${ }^{3} J_{\mathrm{HH}}=7.6 \mathrm{~Hz}, 1 \mathrm{H}, \mathrm{H}_{\mathrm{ar}}$ ), 7.21-7.32 (br m, $4 \mathrm{H}, \mathrm{H}_{\mathrm{ar}}$ ), 7.11 (br m, $4 \mathrm{H}, \mathrm{H}_{\mathrm{ar}}$ ), 6.94 (br m, $1 \mathrm{H}, \mathrm{H}_{\mathrm{ar}}$ ), $5.80(\mathrm{~s}, 1 \mathrm{H}, \mathrm{NH}), 1.46(\mathrm{~s}, 6 \mathrm{H}$, $\mathrm{CH}_{3}$ ). ${ }^{13} \mathrm{C}$ NMR (acetone-d $\left.6,126 \mathrm{MHz}\right) \delta(\mathrm{ppm}): 155.9(\mathrm{C})$, 153.8 (C), 144.7 (C), 144.2 (C), 140.3 (C), 132.5 (C), 130.0 $(\mathrm{CH}), 127.7(\mathrm{CH}), 128.3(\mathrm{CH}), 127.1(\mathrm{CH}), 126.7(\mathrm{CH}), 123.2$ $(\mathrm{CH}), 121.6(\mathrm{CH}), 120.9(\mathrm{CH}), 119.7(\mathrm{CH}), 117.8(\mathrm{CH}), 117.1$ $(\mathrm{CH}), 112.4(\mathrm{CH}), 47.3(\mathrm{C}), 27.5\left(\mathrm{CH}_{3}\right)$. ESI-MS (+10 V, $\left.\mathrm{MeOH}, 0.1 \% \mathrm{NH}_{4} \mathrm{OAc}\right): \mathrm{m} / \mathrm{z} 286.3[\mathrm{M}+\mathrm{H}]^{+}$.

$N$-(4'-Iodo-2,2',6,6'-tetramethyl-[1,1'-biphenyl]-4-yl)- $N$ phenylnaphthalen-1-amine (2a): In a flame dried Schlenkflask 4,4'-diiodo-2,2',6,6'-tetramethyl-1,1'-biphenyl (8.35 g, $18.07 \mathrm{mmol}, 200 \mathrm{~mol} \%$ ) and palladium(II)acetate $(61 \mathrm{mg}, 0.27$ $\mathrm{mmol}, 3 \mathrm{~mol} \%)$ were dissolved in dry toluene $(180 \mathrm{~mL})$. After addition of tri-tert-butylphosphine solution in toluene $(1.4 \mathrm{~mL}$, $1 \mathrm{~mol} \mathrm{~L}^{-1}, 1.4 \mathrm{mmol}, 15 \mathrm{~mol} \%$ ) the color turned from yellow to orange and the solution was continuously stirred. Within 15 min, the color disappeared and sodium tert-butoxide $(1.04 \mathrm{~g}$, $10.82 \mathrm{mmol}, 120 \mathrm{~mol} \%$ ) were added in one portion. The mixture was heated in an oil bath $\left(105^{\circ} \mathrm{C}\right)$ and $N$-naphthylaniline $(1.98 \mathrm{~g}, 9.03 \mathrm{mmol})$ dissolved in toluene $(30 \mathrm{~mL})$ were added drop wise. During the addition, a white solid of sodium iodide precipitates. Stirring and heating continued overnight. The precipitate was filtered off with a Büchner funnel and the solvent was removed with a rotary evaporator and dried in vacuum. Column chromatography with hexane/chloroform (4:1) and silica (K60) was applied to recover un-reacted diiodotetramethyl-biphenyl and isolate the product $(3.50 \mathrm{~g}, 6.56$ mmol, $\left.71 \%, \mathrm{R}_{\mathrm{f}}=0.44\right)$.

m.p. $140{ }^{\circ} \mathrm{C} . \mathrm{C}_{32} \mathrm{H}_{28} \mathrm{IN}\left(553.48 \mathrm{~g} \mathrm{~mol}^{-1}\right)$ : calcd. (\%) C 69.44, H 5.10, N 2.53; found: $\mathrm{C} 70.47, \mathrm{H} 5.10, \mathrm{~N} 2.83 .{ }^{1} \mathrm{H}$ NMR $\left(\mathrm{CDCl}_{3}, 500 \mathrm{MHz}\right) \delta(\mathrm{ppm}): 7.97\left(\mathrm{~d},{ }^{3} J_{\mathrm{HH}}=8.5 \mathrm{~Hz}, 1 \mathrm{H}, \mathrm{H}_{\mathrm{ar}}\right)$, $7.88\left(\mathrm{~d},{ }^{3} J_{\mathrm{HH}}=8.2 \mathrm{~Hz}, 1 \mathrm{H}, \mathrm{H}_{\mathrm{ar}}\right), 7.76\left(\mathrm{~d},{ }^{3} J_{\mathrm{HH}}=8.2 \mathrm{~Hz}, 1 \mathrm{H}\right.$, $\left.\mathrm{H}_{\mathrm{ar}}\right)$, 7.44-7.50 (m, $\left.2 \mathrm{H}, \mathrm{H}_{\mathrm{ar}}\right), 7.46(\mathrm{~s}, 2 \mathrm{H}, \mathrm{CH}), 7.33-7.37(\mathrm{~m}$, $\left.2 \mathrm{H}, \mathrm{H}_{\mathrm{ar}}\right), 7.16-7.20\left(\mathrm{~m}, 2 \mathrm{H}, \mathrm{H}_{\mathrm{ar}}\right), 6.98-7.00\left(\mathrm{~m}, 2 \mathrm{H}, \mathrm{H}_{\mathrm{ar}}\right)$, 6.88-6.92 (m, $\left.1 \mathrm{H}, \mathrm{H}_{\mathrm{ar}}\right), 6.80(\mathrm{~s}, 2 \mathrm{H}, \mathrm{CH}), 1.88\left(\mathrm{~s}, 6 \mathrm{H}, \mathrm{CH}_{3}\right)$, $1.72\left(\mathrm{~s}, 6 \mathrm{H}, \mathrm{CH}_{3}\right) .{ }^{13} \mathrm{C} \mathrm{NMR}\left(\mathrm{CDCl}_{3}, 126 \mathrm{MHz}\right) \delta(\mathrm{ppm})$ : 148.7 (C), 147.1 (C), 143.7 (C), 139.6 (C), 138.6 (C), 136.2 $(\mathrm{CH}), 136.1(\mathrm{C}), 135.3(\mathrm{C}), 132.7(\mathrm{C}), 131.3(\mathrm{C}), 129.0(\mathrm{CH})$, $128.3(\mathrm{CH}), 127.1(\mathrm{CH}), 126.4(\mathrm{CH}), 126.2(\mathrm{CH}), 126.2(\mathrm{CH})$, $126.0(\mathrm{CH}), 124.4(\mathrm{CH}), 121.4(\mathrm{CH}), 121.1(\mathrm{CH}), 92.4(\mathrm{CI})$, $20.0\left(\mathrm{CH}_{3}\right), 19.4\left(\mathrm{CH}_{3}\right)$. ESI-MS $(+20 \mathrm{~V}, \mathrm{MeOH}, 0.1 \%$ $\left.\mathrm{NH}_{4} \mathrm{OAc}\right): m / z$ 554.3.2 $[\mathrm{M}+\mathrm{H}]^{+}$.

$N$-(4'-Iodo-2,2',6,6'-tetramethyl-[1,1'-biphenyl]-4-yl)-9,9dimethyl- $\mathrm{N}$-phenyl-9H-fluoren-3-amine (2b): In a flame dried Schlenk-flask 4,4'-diiodo-2,2',6,6'-tetramethyl-1,1'biphenyl (11.46 g, $24.80 \mathrm{mmol}, 200 \mathrm{~mol} \%)$ and palladium(II)acetate ( $84 \mathrm{mg}, 0.37 \mathrm{mmol}, 3 \mathrm{~mol} \%$ ) were dissolved in dry toluene $(300 \mathrm{~mL})$. After addition of tri-tert-butylphosphine solution in toluene $\left(1.9 \mathrm{~mL}, 1 \mathrm{~mol} \mathrm{~L}^{-1}, 1.9 \mathrm{mmol}, 15 \mathrm{~mol} \%\right)$ the color turned from yellow to orange and the solution was further stirred. Within $15 \mathrm{~min}$, the color disappeared and sodium tert-butoxide (1.79 g, $18.63 \mathrm{mmol}, 120 \mathrm{~mol} \%$ ) were added in one portion. The mixture was heated in an oil bath $\left(105^{\circ} \mathrm{C}\right)$ and 9,9-dimethyl- $N$-phenyl-9H-fluoren-3-amine $\quad(3.54 \mathrm{~g}$, $12.40 \mathrm{mmol})$ in toluene $(35 \mathrm{~mL})$ were added drop wise. During the addition, a white solid of sodium iodide precipitated. Stirring and heating continued overnight. The precipitate was filtered off with a Büchner funnel and the solvent was removed with a rotary evaporator and dried in vacuum. Column chromatography with hexane/chloroform (2.5:1) and silica (K60) was applied to recover un-reacted diiodo-tetramethylbiphenyl and isolate the product $(6.16 \mathrm{~g}, 9.94 \mathrm{mmol}, 80 \%$, $\left.\mathrm{R}_{\mathrm{f}}=0.47\right)$.

m.p. $185^{\circ} \mathrm{C} . \mathrm{C}_{37} \mathrm{H}_{34} \mathrm{IN}\left(619.58 \mathrm{~g} \mathrm{~mol}^{-1}\right)$ : calcd. (\%) C 71.73, H 5.53, N 2.26; found: $\mathrm{C} 72.42, \mathrm{H} 6.09, \mathrm{~N} 2.22 .{ }^{1} \mathrm{H}$ NMR $\left(\mathrm{CDCl}_{3}, 500 \mathrm{MHz}\right): \delta=7.63\left(\mathrm{~d},{ }^{3} J_{\mathrm{HH}}=7.3 \mathrm{~Hz}, 1 \mathrm{H}, \mathrm{H}_{\mathrm{ar}}\right), 7.58$ $\left(\mathrm{d},{ }^{3} J_{\mathrm{HH}}=8.0 \mathrm{~Hz}, 1 \mathrm{H}, \mathrm{H}_{\mathrm{ar}}\right), 7.49(\mathrm{~s}, 2 \mathrm{H}, \mathrm{CH}), 7.38(\mathrm{~d}$, $\left.{ }^{3} J_{\mathrm{HH}}=8.2 \mathrm{~Hz}, 1 \mathrm{H}, \mathrm{H}_{\mathrm{ar}}\right), 7.23-7.32\left(\mathrm{~m}, 4 \mathrm{H}, \mathrm{H}_{\mathrm{ar}}\right), 7.14-7.19(\mathrm{~m}$, $\left.3 \mathrm{H}, \mathrm{H}_{\mathrm{ar}}\right), 6.99-7.07\left(\mathrm{~m}, 2 \mathrm{H}, \mathrm{H}_{\mathrm{ar}}\right), 6.89(\mathrm{~s}, 2 \mathrm{H}, \mathrm{CH}), 1.92(\mathrm{~s}, 6$ $\left.\mathrm{H}, \mathrm{CH}_{3}\right), 1.78\left(\mathrm{~s}, 6 \mathrm{H}, \mathrm{CH}_{3}\right), 1.41\left(\mathrm{~s}, 6 \mathrm{H}, \mathrm{CH}_{3}\right) .{ }^{13} \mathrm{C} \mathrm{NMR}$ $\left(\mathrm{CDCl}_{3}, 126 \mathrm{MHz}\right) \delta(\mathrm{ppm}): 154.9(\mathrm{C}), 153.5(\mathrm{C}), 148.0(\mathrm{C})$, 147.4 (C), 146.6 (C), 139.6 (C), 139.0 (C), 138.5 (C), 136.3 (C), $136.2(\mathrm{CH}), 133.9(\mathrm{C}), 133.5(\mathrm{C}), 129.1(\mathrm{CH}), 126.9$ $(\mathrm{CH}), 126.4(\mathrm{CH}), 123.8(\mathrm{CH}), 123.2(\mathrm{CH}), 122.4(\mathrm{CH}), 122.3$ $(\mathrm{CH}), 120.5(\mathrm{CH}), 119.3(\mathrm{CH}), 118.6(\mathrm{CH}), 92.4(\mathrm{C}), 46.7(\mathrm{C})$, 
$27.0\left(\mathrm{CH}_{3}\right), 19.9\left(\mathrm{CH}_{3}\right), 19.5\left(\mathrm{CH}_{3}\right)$ ESI-MS $(+10 \mathrm{~V}, \mathrm{MeOH}$, $\left.0.1 \% \mathrm{NH}_{4} \mathrm{OAc}\right): m / z 620.2[\mathrm{M}+\mathrm{H}]^{+}$.

2,2',2'",3",5",6,6',6'"-Octamethyl- $N 4, N 4$ '"'-di(naphthalen1-yl)-N4,N4'"'-diphenyl-[1,1':4',1":4",1"'-quaterphenyl]-

4,4"'-diamine (8M-4P-NPD): A pressure tube was charged with compound 2a (524 mg, $0.982 \mathrm{mmol})$, copper bronze (254 $\mathrm{mg})$, and degassed DMF $(1.0 \mathrm{~mL})$. The tube was sealed and heated to $250^{\circ} \mathrm{C}$ for $40 \mathrm{~h}$ under stirring. After cooling to ambient temperature $10 \mathrm{~mL}$ of methanol followed by water $(10$ $\mathrm{mL}$ ) were added and the precipitating white solid was filtered off. Column chromatography with cyclohexane/toluene as eluent $(2.5: 1)$ was applied to obtain the product as a colorless solid (283 $\mathrm{mg} 0.332 \mathrm{mmol}, 68 \%, \mathrm{R}_{\mathrm{f}}=0.47$ ).

m.p. $305{ }^{\circ} \mathrm{C} . \mathrm{C}_{64} \mathrm{H}_{56} \mathrm{~N}_{2}\left(853.14 \mathrm{~g} \mathrm{~mol}^{-1}\right.$ ): calcd. (\%) C 90.10, H 6.62, N 3.28; found: C 90.16, H 6.67, N 3.15. ${ }^{1} \mathrm{H}$ NMR $\left(\mathrm{CDCl}_{3}, 500 \mathrm{MHz}\right) \delta(\mathrm{ppm}): 8.01\left(\mathrm{~d},{ }^{3} J_{\mathrm{HH}}=8.4 \mathrm{~Hz}, 1 \mathrm{H}, \mathrm{H}_{\mathrm{ar}}\right)$, $7.89\left(\mathrm{~d},{ }^{3} J_{\mathrm{HH}}=8.2 \mathrm{~Hz}, 1 \mathrm{H}, \mathrm{H}_{\mathrm{ar}}\right), 7.77\left(\mathrm{~d},{ }^{3} J_{\mathrm{HH}}=8.2 \mathrm{~Hz}, 1 \mathrm{H}\right.$, $\left.\mathrm{H}_{\mathrm{ar}}\right), 7.40(\mathrm{~s}, 2 \mathrm{H}, \mathrm{CH}), 7.45-7.52\left(\mathrm{~m}, 2 \mathrm{H}, \mathrm{H}_{\mathrm{ar}}\right), 7.36-7.40(\mathrm{~m}$, $\left.2 \mathrm{H}, \mathrm{H}_{\mathrm{ar}}\right), 7.18-7.21\left(\mathrm{~m}, 2 \mathrm{H}, \mathrm{H}_{\mathrm{ar}}\right), 7.01-7.03\left(\mathrm{~m}, 2 \mathrm{H}, \mathrm{H}_{\mathrm{ar}}\right)$, 6.89-6.92 (m, $\left.1 \mathrm{H}, \mathrm{H}_{\mathrm{ar}}\right), 6.87(\mathrm{~s}, 2 \mathrm{H}, \mathrm{CH}), 2.01\left(\mathrm{~s}, 6 \mathrm{H}, \mathrm{CH}_{3}\right)$, $1.80\left(\mathrm{~s}, 6 \mathrm{H}, \mathrm{CH}_{3}\right) .{ }^{13} \mathrm{C} \mathrm{NMR}\left(\mathrm{CDCl}_{3}, 126 \mathrm{MHz}\right) \delta(\mathrm{ppm})$ : 148.9 (C), 146.8 (C), 143.9 (C), 139.2 (C), 138.7 (C), 136.4 $(\mathrm{CH}), 136.3(\mathrm{C}), 135.3(\mathrm{C}), 131.4(\mathrm{C}), 128.9(\mathrm{CH}), 128.2$ $(\mathrm{CH}), 127.1(\mathrm{CH}), 126.4(\mathrm{CH}), 126.1(\mathrm{CH}), 126.0(\mathrm{CH}), 124.5$ $(\mathrm{CH}), 121.6(\mathrm{CH}), 121.2(\mathrm{CH}), 120.8(\mathrm{C}), 20.0\left(\mathrm{CH}_{3}\right)$. ESI-MS $\left(+10 \mathrm{~V}, \mathrm{MeOH}, 0.1 \% \mathrm{NH}_{4} \mathrm{OAc}\right): \mathrm{m} / z 853.8[\mathrm{M}+\mathrm{H}]^{+}$.

\section{N4,N4'"-Bis(9,9-dimethyl-9H-fluoren-2-yl)-}

2,2',2"',3",5',6,6',6'"-octamethyl-N4,N4'"-diphenyl-

[1,1':4',1": $4^{\prime \prime}, 11^{\prime \prime}-$-quaterphenyl]-4,4'"'-diamine

(8M-4P-FPD): A pressure tube was charged with compound 2b (1.72 g, $2.78 \mathrm{mmol})$, copper bronze $(759 \mathrm{mg})$, and degassed DMF $(2.8 \mathrm{~mL})$. The tube was sealed and heated under stirring to $250^{\circ} \mathrm{C}$ for $40 \mathrm{~h}$. After cooling to ambient temperature methanol $(40 \mathrm{~mL})$ followed by water $(40 \mathrm{~mL})$ were added and the precipitating white solid was filtered off. Column chromatography with silica and cyclohexane/toluene as eluent (2.5:1) was applied to obtain the product as a colorless solid (0.92 g, $\left.0.934 \mathrm{mmol}, 67 \%, \mathrm{R}_{\mathrm{f}}=0.46\right)$.

m.p. $316{ }^{\circ} \mathrm{C} . \mathrm{C}_{74} \mathrm{H}_{68} \mathrm{~N}_{2}\left(985.35 \mathrm{~g} \mathrm{~mol}^{-1}\right)$ : calcd. (\%) C $90.20, \mathrm{H}$ 6.96, N 2.84; found: C 89.98, H 7.01, N 3.02. ${ }^{1} \mathrm{H}$ NMR $\left(\mathrm{CDCl}_{3}, 500 \mathrm{MHz}\right) \delta(\mathrm{ppm}): 7.63\left(\mathrm{~d},{ }^{3} J_{\mathrm{HH}}=7.4 \mathrm{~Hz}, 1 \mathrm{H}, \mathrm{H}_{\mathrm{ar}}\right)$, $7.59\left(\mathrm{~d},{ }^{3} J_{\mathrm{HH}}=8.2 \mathrm{~Hz}, 1 \mathrm{H}, \mathrm{H}_{\mathrm{ar}}\right), 7.45(\mathrm{~s}, 2 \mathrm{H}, \mathrm{CH}), 7.39(\mathrm{~d}$, $\left.{ }^{3} J_{\mathrm{HH}}=7.4 \mathrm{~Hz}, 1 \mathrm{H}, \mathrm{H}_{\mathrm{ar}}\right), 7.22-7.32\left(\mathrm{~m}, 5 \mathrm{H}, \mathrm{H}_{\mathrm{ar}}\right), 7.17-7.19(\mathrm{~m}$, $\left.2 \mathrm{H}, \mathrm{H}_{\mathrm{ar}}\right), 7.07-7.10\left(\mathrm{~m}, 1 \mathrm{H}, \mathrm{H}_{\mathrm{ar}}\right), 7.00-7.03\left(\mathrm{~m}, 1 \mathrm{H}, \mathrm{H}_{\mathrm{ar}}\right), 6.93$ (s, $2 \mathrm{H}, \mathrm{CH}), 2.06\left(\mathrm{~s}, 6 \mathrm{H}, \mathrm{CH}_{3}\right), 1.85\left(\mathrm{~s}, 6 \mathrm{H}, \mathrm{CH}_{3}\right), 1.42(\mathrm{~s}, 6$ $\left.\mathrm{H}, \mathrm{CH}_{3}\right) .{ }^{13} \mathrm{C} \mathrm{NMR}\left(\mathrm{CDCl}_{3}, 126 \mathrm{MHz}\right) \delta(\mathrm{ppm}): 154.9(\mathrm{C})$, 153.5 (C), 148.1 (C), 147.5 (C), 146.2 (C), 139.3 (C), 139.1 (C), $138.7(\mathrm{CH}), 136.7(\mathrm{C}), 136.2(\mathrm{C}), 134.8(\mathrm{C}), 133.7(\mathrm{C})$, $129.1(\mathrm{CH}), 126.9(\mathrm{CH}), 126.3(\mathrm{CH}), 126.0(\mathrm{CH}), 123.7(\mathrm{CH})$, $123.4(\mathrm{CH}), 123.1(\mathrm{CH}), 122.4(\mathrm{CH}), 122.1(\mathrm{CH}), 120.5$ $(\mathrm{CH}), 119.3(\mathrm{CH}), 118.5 / \mathrm{CH}), 46.8\left[\mathrm{C}\left(\mathrm{CH}_{3}\right)\right], 27.1\left(\mathrm{CH}_{3}\right), 20.1$ $\left(\mathrm{CH}_{3}\right), 20.0\left(\mathrm{CH}_{3}\right)$. ESI-MS $\left(+20 \mathrm{~V}, \mathrm{MeOH}, 0.1 \% \mathrm{NH}_{4} \mathrm{OAc}\right)$ : $\mathrm{m} / \mathrm{z} 985.8[\mathrm{M}+\mathrm{H}]^{+}$.

Single-crystal $\mathrm{X}$-ray structure determination of 8M-4P-FPD: Single crystals suitable for the X-ray diffraction study were obtained from toluene solution. The crystallographic data were collected on a Bruker Nonius Kappa CCD diffractometer using graphite-monochromated Mo-K $\alpha \quad(\lambda=$ $0.71073 \AA$ ) radiation at $193 \mathrm{~K}$. SADABS ${ }^{36}$ was used to perform area-detector scaling and absorption corrections. The structures were solved by direct methods using $\operatorname{Sir} 97^{37}$ and refined by full-matrix least-squares techniques against $F_{\mathrm{o}}{ }^{2}$ by using SHELXL-97 $7^{38}$. All non-hydrogen atoms were refined anisotropically. Hydrogen atom positions were generated by their idealized geometry and refined within a riding model. The absolute structure was determined from anomalous dispersion effects and verified according to Flack. ${ }^{39}$

Cyclic voltammetry was recorded on a Metrohm $\mu$-Autolab instrument in a single-component cell under a nitrogen atmosphere. A typical three electrode configuration with an inlaid platinum disk as working electrode, platinum wire as counter electrode, and a silver rod coated electrochemically with $\mathrm{AgCl}$ was used. The measurements were performed with a scan rate of $100 \mathrm{mV} \mathrm{s}^{-1}$ in degassed dry dichloromethane (HPLC quality) with tetra- $n$-butylammonium hexafluorophosphate (TBAPF, re-crystalized from ethanol, $0.1 \mathrm{~mol} \mathrm{~L}^{-1}$ ) as electrolyte.

As an absolute reference, the oxidation potential of ferrocene was determined in the same solvent, giving $0.40 \mathrm{~V}$. Polarization shifts of all compounds were estimated from the radius of each ion in the form ${ }^{28} \mathrm{P}_{+}=\mathrm{e}^{2} /\left(4 \pi_{0} \mathrm{r}_{\text {ion }}\right)(1-1 / \varepsilon)$. For the three model compounds, the ionic radii were estimated by assuming that their density coincides with the crystalline phase of $8 \mathrm{M}-4 \mathrm{P}-\mathrm{FPD}$, and by equating the volume per molecule with a sphere of radius $r_{\text {ion }}$. For ferrocene, a volume per molecule of $\mathrm{V}_{0}=205 \AA^{3}$ was deduced from the respective crystal phase ${ }^{40}$, giving $\mathrm{r}_{\text {ion }}=3.66 \AA$, and together with the dielectric constant $\varepsilon=8.93$ of dichloromethane, for $\mathrm{Fc} / \mathrm{Fc}^{+}$the polarization shift of the ionization potential amounts to $\mathrm{P}_{+}=1.75 \mathrm{eV}$.

Together with the ionization potential of a free ferrocene molecule of $\mathrm{IP}=6.64 \mathrm{eV}^{41}$, the modified ionization potential in dichloromethane occurs at $4.89 \mathrm{eV}$ below vacuum, placing the reference voltage $0 \mathrm{~V}$ of our electrochemical cell at $4.49 \mathrm{~V}$ below vacuum.

Fluorescence spectra were taken with a FSP920 fluorescence spectrometer (Edinburgh Instruments). For $\operatorname{Ir}(\mathrm{ppy})_{2}$ (acac), $8 \mathrm{wt} \%$ of $\operatorname{Ir}(\mathrm{ppy})_{2}(\mathrm{acac})$ were doped into a TCTA matrix to avoid concentration quenching.

Phosphorescence: For phosphorescence (gated luminescence) measurements samples were excited with a pulsed YAG laser emitting at $355 \mathrm{~nm}$ (EKSPLA) at $45^{\circ}$ angle to the sub-strate plane. Emission was focused onto a spectrograph and detected on a gated iCCD camera (Stanford Computer Optics) with sub nanosecond resolution. Mercury Argon light source was used to calibrate wavelength position, and NIST traceable Tungsten Halogen white light source was used to calibrate camera spectral response. For low temperature measurements samples were placed in the displex cryostat.

Photoluminescence quantum yield (PL-QY) of films were measured using an integrated sphere and Jobin Yvon Fluoromax-3 fluorimeter. ${ }^{42}$ System accuracy was checked by measuring sublimed $100 \mathrm{~nm}$ tris(8-quinolionolato)aluminium(III) films whose PL-QY have already been reported. ${ }^{43}$ Comparable values were obtained.

Quantum chemical calculations: Theoretical studies of the molecular geometries and their transition energies have been performed with a time-dependent self-consistent charge density-functional theory based tight-binding method, TD-SCC$\mathrm{DFTB}^{44-48}$, and with the hybrid functional B3LYP. Both ap- 
proaches agree qualitatively, and all theoretical considerations discussed here are based on geometry optimizations at the B3LYP/6-31G(d) level and on transition energies calculated with time-dependent density functional theory (TD-DFT) using the same functional and variational basis set.

OLED fabrication: Organic materials were commercially purchased and purified by vacuum gradient sublimation. Before device fabrication, pre-structured ITO coated glass substrates (Thin film devices Inc.) were cleaned using ultrasonic treatment in N-Methyl-2-pyrrolidon, distilled water, and ethanol. Organic and metal layers are deposited by thermal evaporation in a UHV chamber (Kurt J. Lesker Co.) at a base pressure of $10^{-7}$ mbar without breaking the vacuum. Evaporation rates and thicknesses of all layers were measured in situ via quartz crystals. Doping was achieved by co-evaporation. After processing, OLEDs were immediately encapsulated in nitrogen atmosphere using glass lids and a UV-curing epoxy resin. The active area of all devices is $6.49 \mathrm{~mm}^{2}$.

\section{OLED stacks:}

The layer structure of the 4P-NPD TH OLEDs (cf. Fig. 1b) was glass $(1.1 \mathrm{~mm}) /$ ITO $(90 \mathrm{~nm}) / \mathrm{MeO}-\mathrm{TPD}: \mathrm{F} 6-\mathrm{TCNNQ}$ $(55 \mathrm{~nm}, 2 \mathrm{wt} \%) /$ Spiro-TAD $(10 \mathrm{~nm}) / 4 \mathrm{P}-\mathrm{NPD}: \operatorname{Ir}(\mathrm{MDQ})_{2}(\mathrm{acac})$ or 4P-NPD:Ir(ppy) $)_{2}$ (acac) $(5 \mathrm{~nm}, 5 \mathrm{wt} \%) / /$ BPhen $(10 \mathrm{~nm}) /$ BPhen:Cs (35 nm)/ Al (100 nm).

The layer structure of the three blue OLEDs (cf. Fig. 9a) was (i) glass $(1.1 \mathrm{~mm}) /$ ITO $(90 \mathrm{~nm}) / \mathrm{MeO}-\mathrm{TPD}: F 6-T C N N Q$ (20 nm, 2wt\%)/ Spiro-TAD (10 nm)/ 4P-NPD (10 nm)/ BPhen $(10 \mathrm{~nm}) /$ BPhen:Cs $(35 \mathrm{~nm}) / \mathrm{Al}(100 \mathrm{~nm})$, (ii) glass $(1.1 \mathrm{~mm}) /$ ITO (90 nm)/ MeO-TPD:F6-TCNNQ (20 nm, 2wt\%)/ SpiroTAD (10 nm)/ 8M-4P-NPD (10 nm)/ TPBI (10 nm)/ BPhen:Cs $(35 \mathrm{~nm}) / \mathrm{Al}(100 \mathrm{~nm})$, and (iii) glass $(1.1 \mathrm{~mm}) / \mathrm{ITO}(90 \mathrm{~nm}) /$ MeO-TPD:F6-TCNNQ (20 nm, 2wt \%)/ TAPC $(10 \mathrm{~nm}) /$ 8M-4P-FPD (10 nm)/ SPPO1 (10 nm)/ BPhen:Cs (35 nm)/ Al $(100 \mathrm{~nm})$.

The green-blue TH OLEDs consisted of (i) glass $(1.1 \mathrm{~mm}) /$ ITO $(90 \mathrm{~nm}) / \mathrm{MeO}-\mathrm{TPD}: F 6-T C N N Q(55 \mathrm{~nm}, 2 \mathrm{wt} \%) / \mathrm{Spi}-$ ro-TAD $(10 \mathrm{~nm}) / 8 \mathrm{M}-4 \mathrm{P}-\mathrm{NPD}: \operatorname{Ir}(\mathrm{ppy})_{2}$ (acac) $(5 \mathrm{~nm}, 5 \mathrm{wt} \%) /$ 8M-4P-NPD $(3,5,7$, or $9 \mathrm{~nm}) /$ TPBI $(10 \mathrm{~nm}) /$ BPhen:Cs $(55 \mathrm{~nm}) / \mathrm{Al}(100 \mathrm{~nm})$ and (ii) glass $(1.1 \mathrm{~mm}) / \mathrm{ITO}(90 \mathrm{~nm}) /$ MeO-TPD:F6-TCNNQ (55 nm, 2wt \%)/ TAPC (10 nm)/ 8M-4P-FPD:Ir(ppy) $)_{2}$ (acac) $(5 \mathrm{~nm}, 5 \mathrm{wt} \%) / 8 \mathrm{M}-4 \mathrm{P}-\mathrm{FPD}(3,5$, or $7 \mathrm{~nm}) /$ SPPO1 $(10 \mathrm{~nm}) /$ BPhen:Cs $(55 \mathrm{~nm}) / \mathrm{Al}(100 \mathrm{~nm})$.

OLED characterization: All OLED characterizations were done in air and under ambient temperature. Current-voltageluminance curves were measured using a source measure unit (Keithley SMU 2400) and a calibrated Si-photodiode. Spectral radiance was recorded with a calibrated spectrometer (Instrument Systems GmbH CAS140). Angular dependent measurements were performed with a self-made and self-calibrated spectro-goniometer setup including an Ocean Optics USB 4000 miniature fiber optic spectrometer. Efficiencies were calculated using the absolute forward emission spectrum and the angular dependent radiant intensity recorded by the goniometer.

\section{AUTHOR INFORMATION}

\section{Corresponding Author}

* E-mail: simone.hofmann@iapp.de

\section{Present Addresses}

$\Pi$ Novaled AG, Tatzberg 49, 01307 Dresden, Germany

\# Fraunhofer Institute for Photonic Microsystems IPMS, MariaReiche-Str. 2, 01109 Dresden, Germany

$\Sigma$ Department of Physics, Kent State University, Kent, 105 Smith Hall, Ohio 44242

$\Gamma$ School of Physics \& Astronomy, University of St Andrews, North Haugh, St Andrews, KY16 9SS, Scotland, UK

\section{Author Contributions}

The manuscript was written through contributions of all authors. All authors have given approval to the final version of the manuscript.

\section{Funding Sources}

The work leading to these results has received funding from the European Community's Seventh Framework Programme under grant number $\mathrm{n}^{\circ} \mathrm{FP7}-224122$ (OLED100.eu).

\section{Notes}

The authors declare no competing financial interest.

\section{ACKNOWLEDGMENT}

The authors thank Annette Petrich for material sublimation, the IAPP Lesker team for device fabrication, and Novaled AG (Dresden) for providing organic materials. Simonas Krotkus is acknowledged for fruitful discussion.

\section{ABBREVIATIONS}

CIE, Commission Internationale de l'Eclairage 1931; CV, cyclic voltammetry; DFT, density functional theory; DMF, dimethylformamid; EA, electron affinity; EML, emission layer; EBL, electron blocking layer; ETL, electron transport layer; EQE, external quantum efficiency; HBL, hole blocking layer; HOMO, highest occupied molecular orbital; HTL, hole transport layer; IP, ionization potential; IVL, current-voltage-luminance; LUMO, lowest unoccupied molecular orbital; OLED, organic light-emitting diode; PL, photoluminescence; PL-QY photoluminescence quantum yield; TH, triplet harvesting; UHV, ultra-high vacuum; XRD, Xray diffraction

\section{MATERIALS}

4P-NPD, N,N'-di-1-naphthalenyl-N,N'-diphenyl$\left[1,1^{\prime}: 4\right.$ ',1' $: 4$ ', 1 ',' -quaterphenyl]-4,4"', diamine; 8M-4PNPD, 2,2',2"',3",5",6,6',6"'-octamethyl-N4,N4"'-di(naphthalen1-yl)-N4,N4"'-diphenyl-[1,1':4',1":4",1"'-quaterphenyl]-4,4"'diamine; 8M-4P-FPD, N4,N4"'-bis(9,9-dimethyl-9H-fluoren2-yl)-2,2',2"',3",5",6,6',6"'-octamethyl-N4,N4"'-diphenyl[1,1':4',1":4",1'"-quaterphenyl]-4,4"'-diamine; BPhen, 4,7diphenyl-1,10-phenanthroline; Cs, cesium; F6-TCNNQ, 2,2'(perfluoronaphthalene-2,6-diylidene)dimalono-nitrile; $\operatorname{Ir}(\mathrm{MDQ})_{2}$ (acac), iridium(III)bis(2-methyldibenzo$[\mathrm{f}, \mathrm{h}]$ chinoxalin)(acetylacetonate); $\operatorname{Ir}(\mathrm{ppy})_{2}$ (acac), iridium(III)bis(2-phenylpyridinato-N,C2') acetylacetonate; ITO, indium tin oxide; MeO-TPD, N,N,N',N'-tetrakis(4methoxyphenyl)-benzidine; Spiro-TAD, 2,2',7,7'-tetrakis(N,N-diphenylamino)-9,9'-spirobifluorene; SPPO1, N,N'Di(naphthalene-1-yl)-N,N'-diphenyl-benzi-dine2-

(diphenylphosphoryl)spirofluorene; TAPC, di-[4-(N,N-ditolylamino)-phenyl] cyclohexane; TPBI, 2,2',2”-(1,3,5phenylene)tris(1-phenyl-1H-benzimidazole) 


\section{REFERENCES}

(1) Reineke, S.; Lindner, F.; Schwartz, G.; Seidler, N.; Walzer, K.; Lüssem, B.; Leo, K. Nature 2009, 459, 234.

(2) Hofmann, S.; Thomschke, M.; Lüssem, B.; Leo, K. Optics express 2011, 19, 1250.

(3) Yersin, H.; Rausch, A. F.; Czerwieniec, R.; Hofbeck, T.; Fischer, T. Coordination Chemistry Reviews 2011, 255, 2622.

(4) Adachi, C.; Baldo, M. A.; Thompson, M. E.; Forrest, S. R. Journal of Applied Physics 2001, 90, 5048.

(5) Sasabe, H.; Kido, J. Chemistry of Materials 2011, 23, 621 .

(6) Seifert, R.; Rabelo de Moraes, I.; Scholz, S.; Gather, M. C.; Lüssem, B.; Leo, K. Organic Electronics 2013, 14, 115.

(7) Uoyama, H.; Goushi, K.; Shizu, K.; Nomura, H.; Adachi, C. Nature 2012, 492, 234.

(8) Jankus, V.; Chiang, C.-J.; Dias, F.; Monkman, A. P. Advanced Materials 2013, 25, 1455.

(9) Sun, Y.; Giebink, N. C.; Kanno, H.; Ma, B.; Thompson, M. E.; Forrest, S. R. Nature 2006, 440, 908.

(10) Schwartz, G.; Pfeiffer, M.; Reineke, S.; Walzer, K.; Leo, K. Advanced Materials 2007, 19, 3672.

(11) Schwartz, G.; Reineke, S.; Rosenow, T. C.; Walzer K.; Leo, K. Advanced Functional Materials 2009, $19,1319$.

(12) Rosenow, T. C.; Furno, M.; Reineke, S.; Olthof, S.; Lüssem, B.; Leo, K. Journal of Applied Physics 2010, 108, 113113.

(13) Kondakova, M. E.; Deaton, J. C.; Pawlik, T. D.; Giesen, D. J.; Kondakov, D. Y.; Young, R. H.; Royster, T. L.; Comfort, D. L.; Shore, J. D. Journal of Applied Physics 2010, 107, 014515.

(14) Hung, W.-Y.; Chi, L.-C.; Chen, W.-J.; Chen, Y.-M.; Chou, S.-H.; Wong, K.-T. Journal of Materials Chemistry 2010, 20, 10113.
(15) Brunner, K.; Van Dijken, A.; Börner, H.; Bastiaansen, J.; Kiggen, N.; Langeveld, B. J. Am. Chem. Soc. 2004, 126, 6035.

(16) Yang, X.; Zheng, S.; Bottger, R.; Chae, H. S.; Tanaka, T.; Li, S.; Mochizuki, A. Journal of Physical Chemistry 2011, 115, 14347.

(17) Zheng, C.-J.; Wang, J.; Ye, J.; Lo, M.-F.; Liu, X.-K.; Fung, M.-K.; Zhang, X.-H.; Lee, C.-S. Advanced Materials 2013.

(18) Schwartz, G.; Reineke, S.; Walzer, K.; Leo, K. Applied Physics Letters 2008, 92, 053311.

(19) Blochwitz, J.; Pfeiffer, M.; Fritz, T.; Leo, K. Applied Physics Letters 1998, 73, 729.

(20) Hofmann, S.; Rosenow, T.; Gather, M. C.; Lüssem, B.; Leo, K. Physical Review B 2012, 85, 245209.

(21) Wünsche, J.; Reineke, S.; Lüssem, B.; Leo, K. Physical Review B 2010, 81, 245201.

(22) Hofmann, S.; Furno, M.; Lüssem, B.; Leo, K.; Gather, M. C. Physica Status Solidi (a) 2013, 210, 1467.

(23) Liehm, P.; Murawski, C.; Furno, M.; Lüssem, B.; Leo, K.; Gather, M. C. Applied Physics Letters 2012, 101, 253304.

(24) Scholz, R.; Gisslén, L.; Himcinschi, C.; Vragović, I.; Calzado, E.M.; Louis, E.; San Fabián Maroto, E.; Díaz-García, M.A. J. Phys. Chem. A 2009, 113, 315.

(25) Scholz, R.; Hofmann S.; et al., in preparation.

(26) Wu, C.-H.; Chien, C.-H.; Hsu, F.-M.; Shih, P.-I.; Shu, C.-F. Journal of Materials Chemistry 2009, $19,1464$.

(27) Pabst, M.; Sundholm, D.; Koehn, A. The journal of physical chemistry. A 2012, 116, 15203.

(28) Weller, A. Z. Phys. Chem. Neue Folge 1982, 133, 93.

(29) Scholz, R.; Luschtinetz, R.; Seifert, G.; JägelerHoheisel, T.; Körner, C.; Leo, K.; Rapacioli, M. J. Phys. Condens. Matt. 2013, 25, 473201. 
(30) Duhm, S.; Heimel, G.; Salzmann, I.; Glowatzki, H.; Johnson, R. L.; Vollmer, A.; Rabe, J. P.; Koch, N. Nature Materials 2008, 7, 326.

(31) Vonlanthen, D.; Rotzler, J.; Neuburger, M.; Mayor, M. European Journal of Organic Chemistry 2010, 2010, 120.

(32) Baldo, M. A.; Adachi, C.; Forrest, S. R. Physical Review B 2000, 62, 10967.

(33) Jankus, V.; Winscom, C.; Monkman, A. P. Journal of Physics: Condensed Matter 2010, 22, 185802.

(34) Loudon, R: The Quantum Theory of Light. Clarendon, Oxford, 1983.

(35) Wei, W.; Djurovich, P. I.; Thompson, M. E. Chemistry of Materials 2010, 22, 1724.

(36) Bruker SADABS User Manual - Area Detector Absorption and Other Corrections V2.03; Delft, Netherlands, 2002.

(37) Altomare, A.; Burla, M. C.; Camalli, M.; Cascarano, G. L.; Giacovazzo, C.; Guagliardi, A.; Moliterni, A. G. G.; Polidori, G.; Spagna, R. Journal of Applied Crystallography 1999, 32, 115.

(38) Sheldrick, G. M. SHELXL-97 Program for the Refinement of Crystal Structures; Universität Göttingen, Göttingen (Germany), 1997.
(40) Dunitz, J. D.; Orgel, L. E.; Rich, A. Acta Crystallographica 1956, 9, 373

(41) Ryan, M. F.; Eyler, J. R.; Richardson, D. E. Journal of the American Chemical Society 1992, 114, 8611

(42) Pålsson, L.-O.; Monkman, A. P. Advanced Materials 2002, 14, 757 .

(43) Kawamura, Y.; Sasabe, H.; Adachi, C. Japanese Journal of Applied Physics 2004, 43, 7729.

(44) Seifert, G.; Porezag, D.; Frauenheim, T. International Journal of Quantum Chemistry 1996, 58, 185.

(45) Porezag, D.; Frauenheim, T.; Köhler, T.; Seifert, G.; Kaschner, R. Physical Review B 1995, 51, 12947.

(46) Elstner, M.; Porezag, D.; Jungnickel, G.; Elsner, J.; Haugk, M.; Frauenheim, T.; Suhai, S.; Seifert, G. Physical Review B 1998, 58, 7260.

(47) Niehaus, T.; Suhai, S.; Della Sala, F.; Lugli, P.; Elstner, M.; Seifert, G.; Frauenheim, T. Physical Review B 2001, 63, 085108.

(48) Niehaus, T. A. Journal of Molecular Structure: THEOCHEM 2009, 914, 38.

(39) Flack, H. D. Acta Cryst. 1983, A39, 876.

Authors are required to submit a graphic entry for the Table of Contents (TOC) that, in conjunction with the manuscript title, should give the reader a representative idea of one of the following: A key structure, reaction, equation, concept, or theorem, etc., that is discussed in the manuscript. Consult the journal's Instructions for Authors for TOC graphic specifications.

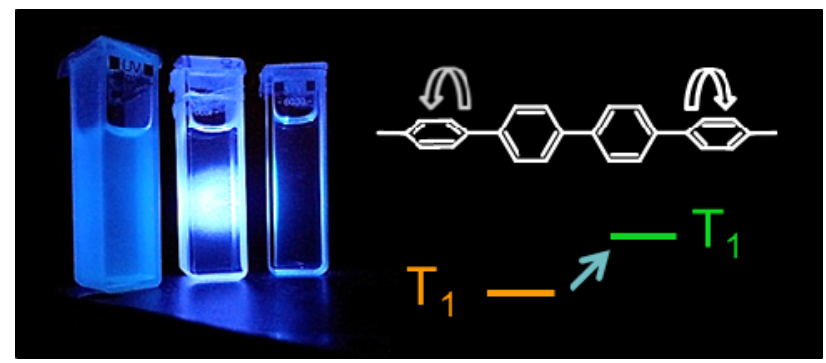

